\title{
A nuclear role for ARGONAUTE-2 in regulation of neuronal alternative polyadenylation
}

Revital Ravid ${ }^{1}$, Aviad Siany ${ }^{1}$, Natalia Rivkin ${ }^{1}$, Chen Eitan $^{1}$, Hagai Marmor-Kollet ${ }^{1}$, Eran Yanowski ${ }^{1}$, Alon Savidor ${ }^{2}$, Yishai Levin ${ }^{2}$, Gregor Rot $^{3}$, Gunter Meister ${ }^{4}$, Eran Hornstein $^{1,5}$

1 Department of Molecular Genetics, Weizmann Institute of Science, Rehovot, Israel 2 de Botton Institute for Protein Profiling, The Nancy and Stephen Grand Israel National Center for Personalized Medicine, Weizmann Institute of Science, Rehovot, Israel

3 Institute of Molecular Life Sciences of the University of Zurich and Swiss Institute of Bioinformatics, Zurich, Switzerland

4 Regensburg Center for Biochemistry (RCB), Laboratory for RNA Biology, University of Regensburg, Regensburg, Germany

5 Correspondence should be addressed to: Eran Hornstein:

eran.hornstein@weizmann.ac.il

Eran Hornstein, $\mathrm{PhD}, \mathrm{MD}$.

Department of Molecular Genetics,

Weizmann Institute of Science,

Herzl Street 1, 76100 Rehovot, Israel,

Phone: 0097289346215 FAX: 0097289344108

Email: eran.hornstein@weizmann.ac.il

Running title: $\mathrm{AGO} 2$ regulates neuronal alternative polyadenylation 


\begin{abstract}
Argonaute 2 (AGO2), the effector protein partner of microRNAs (miRNAs) in the cytoplasmic RNA induced silencing complex, is further involved in nuclear RNA processing. However, a role for AGO2 in regulation of alternative polyadenylation was not yet demonstrated. Here, we reveal unexpected abundance of AGO2 in mouse neuronal nuclei and characterize nuclear AGO2 interactors by mass spectrometry. We discover that AGO2 broadly regulated alternative polyadenylation (APA) in neuronal cells. Specifically, we demonstrate how two isoforms of Ret mRNA, which encodes a receptor tyrosine kinase are regulated by AGO2-depenent APA, affecting downstream GDNF signaling in primary motor neurons.
\end{abstract}




\section{Introduction}

Argonaute (AGO) proteins are the direct binding partners of small RNAs and primarily execute small-RNA-guided gene-silencing processes (Bartel, 2004; Hammond et al., 2001; Hock \& Meister, 2008; Liu et al., 2004; Meister, 2013; Meister \& Tuschl, 2004; Tuschl et al., 1999; Zamore et al., 2000). AGO2 is the most abundant among the four mammalian AGO proteins (AGO1-4), facilitating regulatory activities, based on interacting protein co-factors. GW protein trinucleotide repeat-containing gene 6 (TNRC6 A/B/C) are the chief co-factors of AGO2 that are necessary for regulatory activities, such as mRNA deadenylation, decapping and degradation (Eulalio et al., 2008; Fabian et al., 2011; Jakymiw et al., 2005; Liu, Rivas, et al., 2005; Rehwinkel et al., 2005; Zekri et al., 2009). Under normal conditions, AGO2 is primarily in the cytoplasm, in both diffuse form and in cytoplasmic foci termed processing bodies (Pbodies) (Eulalio et al., 2007; Liu, Valencia-Sanchez, et al., 2005; Schraivogel et al., 2015; Sen \& Blau, 2005).

However, the presence of AGO proteins was reported also in the nucleus (Bottini et al., 2017; Chu et al., 2010; Gagnon et al., 2014; Janowski et al., 2006; Kalantari et al., 2016; Robb et al., 2005; Rudel et al., 2008; Sarshad et al., 2018; Wei et al., 2014), where they are involved in nuclear microRNA (miRNA)-mediated genesilencing (Meister, 2013; Sarshad et al., 2018), transcriptional silencing (Benhamed et al., 2012; Chu et al., 2010; Janowski et al., 2006; Janowski et al., 2007) and splicing (Ameyar-Zazoua et al., 2012). The diversified aspects of RNA regulation (reviewed in (Nussbacher et al., 2019)), highlights the flexibility of AGO2 that is based on the specific activities of the associated RNA-binding protein cofactors that are recruited by AGO and TNRC6.

Alternative polyadenylation (APA) is a nuclear processing step of the mRNA 3' end that is executed by a nuclear complex of CPSF and CstF proteins (Danckwardt et al., 2008; Elkon et al., 2013). A canonical polyadenylation sequence is positioned in cis 15-30bp upstream of the polyadenylation site (polyadenylation signal, PAS), and is composed of an AAUAAA consensus sequence or variants thereof (MacDonald \& Redondo, 2002; Tian \& Graber, 2012). APA affects various aspects of RNA metabolism, mRNA stability, nuclear export, cellular localization and translation efficiency. Furthermore, 3'UTR isoforms directly affect the presence of miRNA 
recognition sites (Danckwardt et al., 2008; Elkon et al., 2013; Fu et al., 2018; Tian \& Manley, 2017).

The secreted glial cell derived neurotrophic factor (GDNF) drives neurotrophic signaling that is important for axonal outgrowth, synapse maturation and neuron survival (Airaksinen \& Saarma, 2002; Baudet et al., 2008; Bonanomi et al., 2012; Enomoto et al., 2001; Honma et al., 2010; Kramer et al., 2006; Pachnis et al., 1993; Runeberg-Roos \& Saarma, 2007; Tuttle et al., 2019). Ret proto-oncogene is a tyrosine kinase receptor for GDNF (Romei et al., 2016) that is highly expressed in motor neurons (Baudet et al., 2008; Cintron-Colon et al., 2020; Pachnis et al., 1993). GDNF stimulation triggers RET autophosphorylation on distinct tyrosine residues, and intracellular activation of phosphatidylinositol 3-kinase (PI3-kinase) and mitogenactivated protein kinase (MAPK) pathways, which contribute to neuronal survival (Airaksinen \& Saarma, 2002; Kaplan \& Miller, 2000). Two RET isoforms RET9 and RET51, differ in the C-terminus sequence (Ibanez, 2013; Rossel et al., 1997). Both shorter RET9 and longer RET51 are phosphorylated on Tyr1062, but an additional tyrosine residue at position 1096, is present only at RET51 and can drive activation of GRB2 (Airaksinen \& Saarma, 2002; Ibanez, 2013). The two isoforms differ in expression, intracellular trafficking and stability Consequently, RET9 and RET51, convey distinct signaling properties (de Graaff et al., 2001; Heanue \& Pachnis, 2008; Lee et al., 2003; Richardson et al., 2012; Tsui \& Pierchala, 2010; Wong et al., 2005). Interestingly, RET is differentially expressed and phosphorylated in amyotrophic lateral sclerosis (ALS) models (Kramer \& Liss, 2015; Ryu et al., 2011; Zhang \& Huang, 2006), highlighting a biomedical interest in elucidating the regulation of RET neuronal isoforms.

Here, we describe a novel function of $\mathrm{AGO} 2$ in the nuclear control of alternative polyadenylation, by using unbiased approaches and molecular tools. Our results indicate the involvement of $\mathrm{AGO} 2$ in alternative polyadenylation (APA) in neurons, including in control of the motor neuron-enriched GDNF receptor Ret. 


\section{Results}

\section{AGO2 is abundant in the nucleus of neuronal cells}

To evaluate the nuclear localization of $\mathrm{AGO} 2$ in primary mouse motor neurons, we performed an immunofluorescence study, which revealed substantial AGO2 enrichment in motor neuron nuclei (Figure 1A). This unexpected abundance of AGO2 drove us to explore potential nuclear functions for AGO2. We have used a western blot (WB) analysis of a simple neuroblastoma cell line, NSC-34, and discovered that AGO2 was comparably abundant in nuclear and cytoplasmic fractions (Figure 1B). Accordingly, mass spectrometric (MS) profiling of cellular compartments, revealed that AGO2 abundance in the nucleus of NSC-34 cells, approximated cytoplasmic levels (Figure 1C, Supplementary Table 4, Supplementary Figure 1A, B). Therefore, AGO2 is particularly abundant in the nucleus of primary motor neurons and of a neuronal cell line.
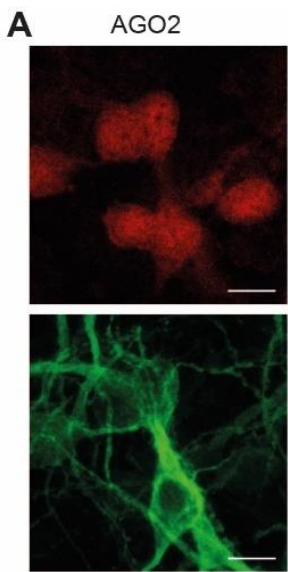

MAP-2
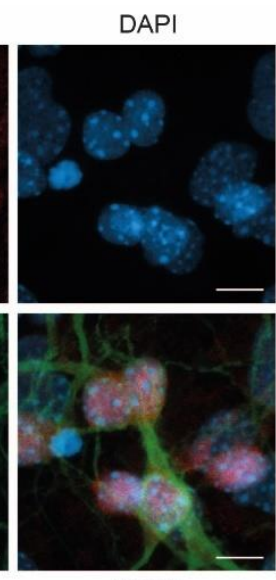

Merge
B
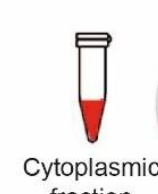
fraction
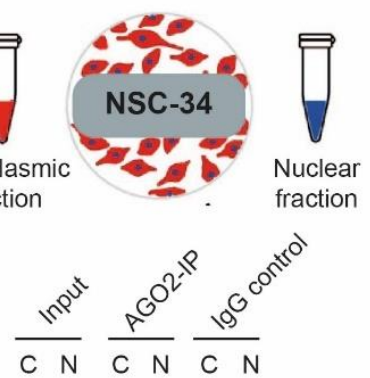

$100 \mathrm{kDa}$

$62 / 69 \mathrm{kDa}$

$55 \mathrm{kDa}$

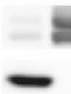

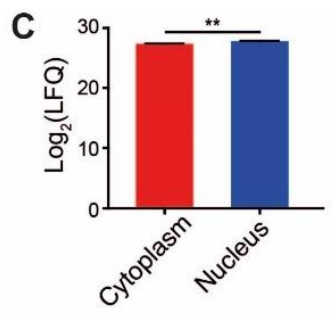

Figure 1. AGO2 is abundant in the nucleus of neuronal cells. (A) Micrographs of mouse primary motor neurons, stained with $\mathrm{AGO} 2$ antibody (red), neuron-specific microtubule associated protein MAP2 (green) and DAPI (blue). Scale bar - 10 $\mu$ m. Mouse primary motor neurons harvested on embryonic day E13.5 and cultured for 7 days before fixation and immunofluorescence analysis. (B) A diagram of NSC-34 subcellular fractionation protocol, and WB analysis of cytoplasmic ' $C$ ' or nuclear ' $N$ ' fractions. Input - lysates, or proteins coimmuno-precipitated with $\mathrm{AGO} 2$ or with IgG-control antibody. GAPDH/LAMIN A/C are cytoplasmic/nuclear markers, respectively. (C) Bar graph, depicting AGO2 mass spectrometry in cytoplasmic or nuclear fractions, identified by 24 unique peptides. Student's $t$-test $(\mathrm{S} 0=0.1$ ) FDR p-value $=0.00546$. 


\section{Identification of AGO2 nuclear interactors}

To isolate nuclear AGO2-interacting proteins, we immunoprecipitated endogenous AGO2 (AGO2-IP) from nuclear NSC-34 fractions and analyzed by mass spectrometry. Data are available via ProteomeXchange with identifier PXD023112. We identified 472 AGO2-interacting proteins, which were enriched in nuclear AGO2-IP by at least two-fold, relative to non-specific IgG-control (q-value $\leq 0.05$, using permutation-based false discovery rate (FDR)). Among AGO2 nuclear interactors, we report the three paralog co-factors TNRC6A, B and $\mathrm{C}$, heterogeneous nuclear ribonucleoproteins (HNRNPs), nuclear paraspeckle components, ribosomal proteins, RNA helicases and RNA-splicing factors (Figure 2A, Supplementary Table 5). Interestingly, FUS, TDP-43, and HNRNPA2B1, whose mutated form is associated with motor neuron diseases also co-immunoprecipitated with AGO2.

Next, we tested if AGO2-interactors are identified in previously-characterized protein networks. The 472 AGO2 interactors are predicted by STRING (Franceschini et al., 2013) to create a dense protein-protein network, that is more prevalent than could be expected at random, when the full nuclear proteome ( 2000 proteins) from the same cells is taken as background ( $\mathrm{p}$-value $<1 \times 10^{-16}$ ). Many nuclear AGO2 interactors are functionally annotated as RNA-binding proteins and involved in a variety of ribonucleoprotein complexes (DAVID Bioinformatics Resources 6.7 (Huang da et al., 2009), Figure 2B). Therefore, nuclear AGO2 in neuronal cells is associated with RNAbinding protein networks.

\section{AGO2 is involved in alternative polyadenylation}

AGO2-nuclear interactors are enriched with proteins that are involved in alternative polyadenylation including direct APA factors CSTF1, CPSF7, , NUDT21, PABPN1, RBBP6; and regulators PTBP1, PTBP2, PTBP3, ELAVL1, ELAVL2, ELAVL4, SRSF3, SRSF7, FUS, TDP-43 and HNRNPA2B1. This enrichment, that is more than can be expected at random, suggests potential functional association of AGO2 and the APA machinery ( $\mathrm{p}$-value $=0.0074$ by hypergeometrical distribution test). We could also demonstrate the co-immunoprecipitation of at least two of the proteins with AGO2, PTBP1 and HNRNPA2B1, by WB analysis (Figure2C). 

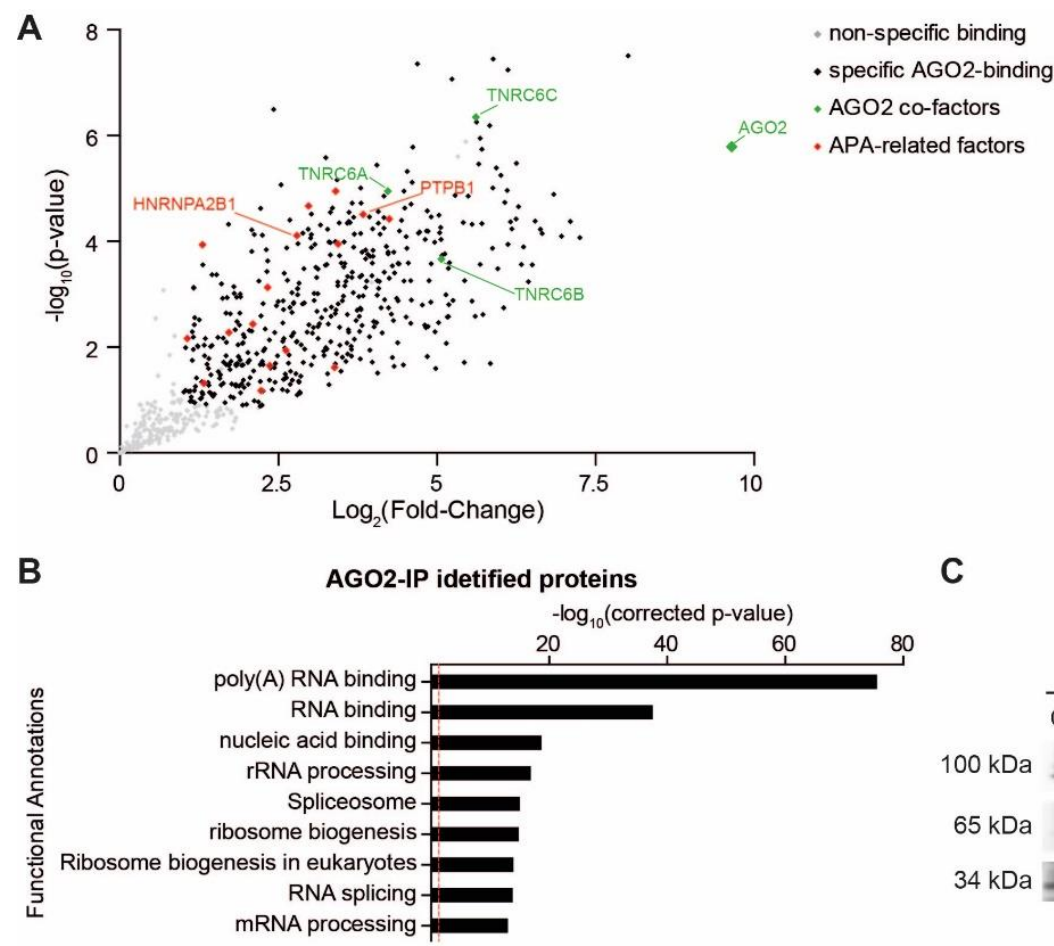

C

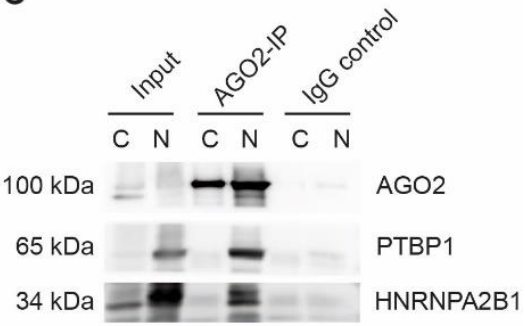

Figure 2. Identification of AGO2 interacting proteins in NSC-34 nuclei. (A) Scatter plot depicting proteins co-immunoprecipitated with $\mathrm{AGO} 2$ and identified by MS analysis. $\mathrm{x}$ - axis: $\log _{2}$ fold change of label-free peptide quantification values in AGO2-IP versus the IgG-control; y axis: $\log _{10}$ of one-tailed Student's t-test p-value. Grey-non-specifically bound proteins; Black -proteins specifically-bound by AGO2; Green TNRC6 A/B/C are AGO2 co-factors; Red proteins with function in alternative polyadenylation. (B) Gene ontology analysis (DAVID 6.7 bioinformatic database, (Huang da et al., 2009)) of 472 nuclear AGO2 interacting proteins, shown as $-\log _{10}$ (Bonferroni corrected p-value) of pathway enrichment (logarithmic scale). Dashed red line indicates a p-value of 0.05. (C) Western blot study of AGO2, PTBP1 and HnRNPA2B1, in cytoplasm ' $\mathrm{C}$ ' and nucleus ' $\mathrm{N}$ ' of NSC-34 after immunoprecipitation with antibody against $\mathrm{AGO} 2$ or non-specific IgG isotype control. Inputs are subcellular fraction lysates without immunoprecipitation. 
To explore the hypothesis that AGO2 regulates APA, we performed next generation sequencing (NGS) of $3^{\prime}$ mRNA from NSC-34 cells, in which AGO2 was knocked-down by siRNA (Supplementary Figure 2). We computed molecular switches, as in (Rot et al., 2017), whereby a proximal (/distal) polyadenylation preference, is reciprocated by a new predominant polyadenylation signal that is positioned more distally (/proximally). A new proximal (/distal) APA site preference results in upregulation of shorter (/longer) 3'UTR, concomitant with downregulation of longer (/shorter) mRNA isoform (Figure 3A, B). We identified a total of 26,816 poly(A) sites, which were annotated to 11,157 mRNAs with at least one 3' end isoform. Of these, 1952 pairs displayed proximal-over-distal polyadenylation preference switch in response to knockdown of $\mathrm{AGO} 2$, whereas 2933 pairs displayed a reverse distalover-proximal preference (Supplementary Table 6). A global transcriptome-wide change in polyadenylation preference was observed (Chi-squared test for the probability of a shift from proximal-to-distal preference or vice versa, $\mathrm{p}$-value $<2.2 \mathrm{E}$ 16, Figure 3C), suggesting that APA regulation is a new and broad function of nuclear AGO2. Next, we focused our attention on 72 candidate transcripts, whose polyadenylation switches was the most significant after correction to multiple hypothesis (Benjamini-Hochberg based FDR adjusted p-value <0.05). Only nine Gencode annotated mRNAs (Frankish et al., 2019), displayed an AGO2-dependent polyadenylation switch and further harbor an AGO2-binding site at the vicinity $( \pm$ 100bps) of the regulated poly-A site (AGO2-CLIP data from (Moore et al., 2015), Table 1).

We tested the polyadenylation switches of these 9 mRNAs by PCR-based 3' rapid amplification of cDNA ends (3' RACE; Supplementary Figure 3). This study revealed two polyadenylated isoforms for four mRNAs, out of the nine studied. Whereas AGO2 favors the proximal polyadenylation isoform of Fam3c, Zwint and Ret, and its knockdown resulted in preference towards the distal (longer) isoform, AGO2 activity contributes to distal Gatad2a polyadenylation (Figure 3D). Taken together, the involvement of $\mathrm{AGO} 2$ in APA regulation is evident via unbiased NGS study and analysis of specific targets. 


\begin{tabular}{l|l|l|l|l|l|l|l}
$\begin{array}{l}\text { Gene } \\
\text { name }\end{array}$ & $\begin{array}{l}\text { Proximal } \\
\text { feature }\end{array}$ & $\begin{array}{l}\text { Distal } \\
\text { feature }\end{array}$ & $\begin{array}{l}\text { Proximal } \\
\text { FC }\end{array}$ & $\begin{array}{l}\text { Distal } \\
\text { FC }\end{array}$ & $\begin{array}{l}\text { Proximal } \\
\text { p-adj }\end{array}$ & $\begin{array}{l}\text { Distal } \\
\text { p-adj }\end{array}$ & $\begin{array}{l}\text { UTR } \\
\text { length } \\
\text { difference }\end{array}$ \\
\hline \hline Cxxc5 & utr3 & utr3 & 2.34 & 0.84 & 0.04496 & 0.03753 & -789 \\
Fam3c & utr3 & utr3 & 0.58 & 1.31 & 0.0223 & 0.00496 & +1369 \\
Gatad2a & utr3 & utr3 & 1.28 & 0.63 & 0.02205 & 0.00949 & -1581 \\
Klc1 & utr3 & utr3 & 0.69 & 1.31 & 0.00019 & 0.00019 & +11818 \\
Map6 & utr3 & utr3 & 0.66 & 1.26 & 0.00587 & 0.00178 & +16918 \\
Pdlim7 & utr3 & exon & 0.59 & 1.65 & 0.00001 & 0 & +8360 \\
Ret & utr3 & utr3 & 0.80 & 1.44 & 0.01754 & 0.01793 & +2819 \\
Trp53bp2 & utr3 & utr3 & 0.65 & 1.51 & 0.04462 & 0.00177 & 651 \\
Zwint & utr3 & utr3 & 0.787 & 2.24 & 0 & 0.00001 & 5798
\end{tabular}

Table 1. AGO2-mediated alternative polyadenylation switches. Nine top hits exhibiting proximal/distal switch after knockdown of $\mathrm{AGO} 2$ with mRNA region wherein the PAS reside; Proximal/Distal FC - fold change of the usage of the chosen PAS between AGO2-KD and control; Proximal/Distal padj - adjusted p-value (correction for multiple hypothesis, FDRbased), for the AGO2-KD vs control comparison of the usage of the chosen PAS; UTR length difference - the difference (in base-pairs) between the proximal and distal PAS chosen as switch, +/- represent lengthening or shortening. 


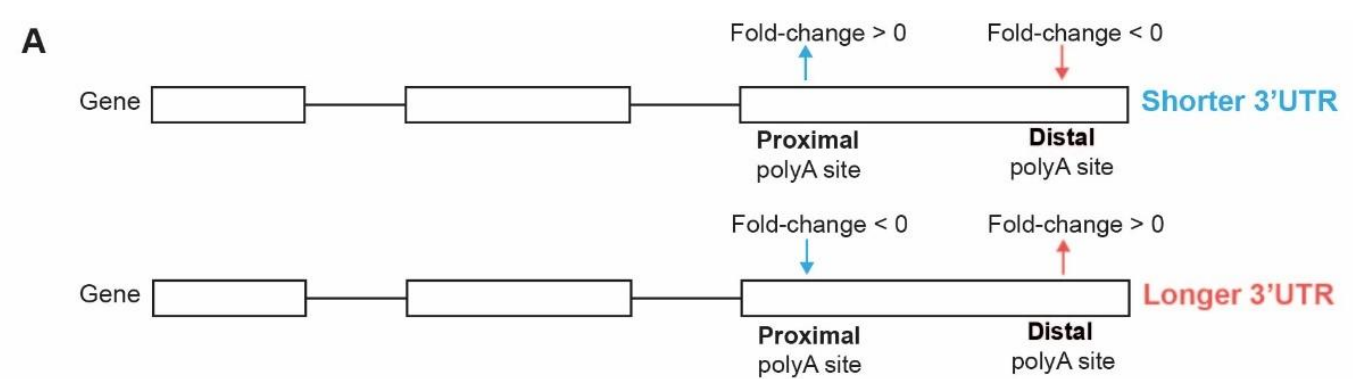

B

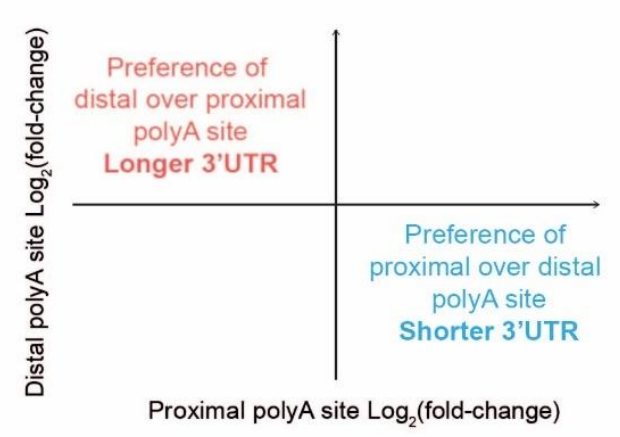

D
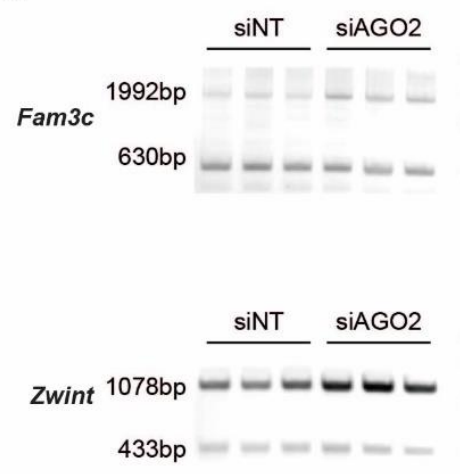

C

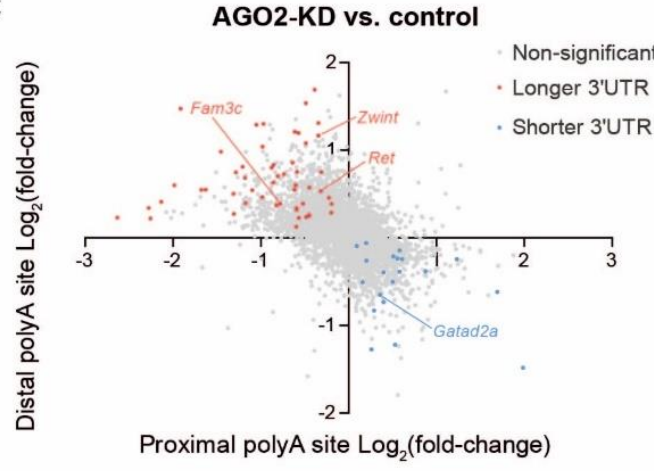

Figure 3. AGO2 activity controls alternative polyadenylation. Diagrams of (A) proximal to distal polyadenylation switch and (B) of data distribution over a scatter plot of proximal ( $\mathrm{x}$ axis) and distal (y-axis) polyadenylation ratio inferred from 3' mRNA-sequencing. (C) Scatter plot of next generation RNA sequencing data, revealing polyadenylation ratio after AGO2 knockdown (siAGO2) vs non-targeting siRNA (siNT). mRNAs elongated/shorted their 3'UTR or were below statistical significance (red/ blue, grey respectively) by FDR-corrected p-values $\leq 0.05$. (D Rapid amplification of cDNA ends (RACE), analysis of 3' RNA polyadenylation preference by gel electrophoresis of RACE-PCR products and bar graph quantification. AGO2 knockdown (siAGO2) vs a non-specific siRNA control (siNT). Band densitometry normalized to controls. Average and SEM, two-tailed Student's t-test p-value $*^{*} \leq 0.05, * * \leq 0.01, * * * \leq 0.001$. Fam $3 c-$ p-value $=0.00097 ;$ Ret - p-value $=0.0035 ;$ Zwint - p-value $=0.0217 ;$ Gatad $2 a-$ pvalue $=0.05$. 


\section{AGO2 mediates RET isoform expression via APA-regulation}

Motor neuron-enriched Ret is a tyrosine-kinase receptor, activated by GDNF ligands (Airaksinen \& Saarma, 2002; Arce et al., 1998; Baudet et al., 2008; Ibanez \& Andressoo, 2017). In response to binding of GNDF, RET dimerizes and autophosphorylates several tyrosine residues at its intracellular domain, which docks downstream effectors (Airaksinen \& Saarma, 2002; Ibanez \& Andressoo, 2017). GDNF-RET signaling promotes motor neuron survival and is essential for neuromuscular junction development (Baudet et al., 2008; Zahavi et al., 2015).

We describe two Ret transcript variants, which correspond to the annotated Ret9 and Ret51 (Carter et al., 2001; Lee et al., 2003), with AGO2 binding sites (Moore et al., 2015), adjacent to Ret polyadenylation sequence (Figure 4A, blue).

To test if AGO2 directly binds Ret in the nucleus, we co-immuno-precipitated AGO2 with associated RNA (AGO2-RIP) from nuclear NSC-34 fraction. We demonstrated comparable levels of Ret, Vimentin and Ptbpl mRNAs, bound to AGO2 in the nucleoplasm, by quantitative PCR (qPCR, Figure 4B). Furthermore, AGO2dependent isoform preference is evident in both nuclear and cytoplasm. Because mRNA undergoes directional nucleo-cytoplasmic export, the upregulation of Ret mRNA in the nucleus, in response to knocking down AGO2, is consistent with APA taking place in the nucleus (Figure 4C).

Next, we quantified the relative usage of two Ret APA cis-regulatory sequences in response to $\mathrm{AGO} 2$ levels, by using a bicistronic luciferase-reporter, similar to the one reported in (Deng et al., 2018). The reporter, which harbors the APA cis-regulatory sequences of Ret mRNA 3', excludes many other potential regulatory elements that may reside on the transcript. The APA reporter assay in N2A cells, revealed that proximal Ret polyadenylation depends on $\mathrm{AGO} 2$ and that $\mathrm{AGO} 2$ knockdown resulted in preference of the distal Ret polyadenylation site (Figure 4D, E).

Finally, we used single-molecule fluorescent in-situ hybridization (smFISH) to test the cellular distribution of the Ret mRNA isoforms in NSC-34 cells and in mouse primary motor neurons (Supplementary Figure 4A, B). smFISH indicated the presence of both Ret mRNA variants in the soma and proximal neurites of the neurons. AGO2 knockdown resulted in a significant increase in total transcript copies and in 
upregulation of the long Ret mRNA variant mRNA, relative to all mRNA forms,

(Figure 4F, G). Therefore, AGO2 regulates Ret mRNA alternative polyadenylation.

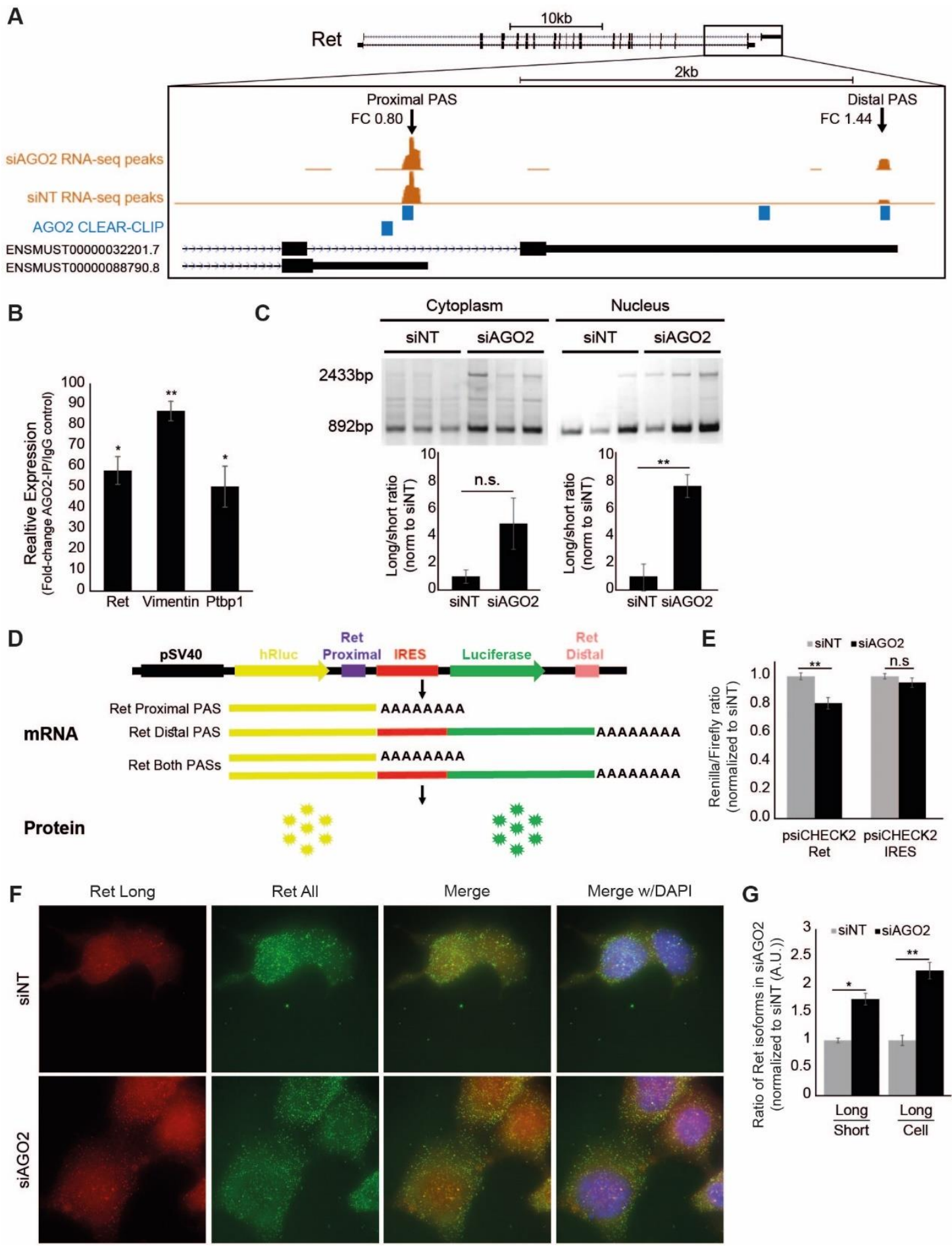

Figure 4. AGO2 controls Ret polyadenylation in a neuronal cell line. (A) Two annotated mRNA variants of the mouse Ret gene, depicted by 3' next generation RNA sequencing reads at the proximal/distal polyadenylation site under basal conditions (siNT) or knockdown of AGO2 (siAGO2), with fold-change for each site (FC). The longer ENSMUST00000032201.7 encodes for Ret51 protein isoform, whereas the shorter, ENSMUST00000088790.8, encodes 
for Ret9. Position of AGO2 binding, at the 3'UTR of Ret mRNA, juxtaposed to the proximal polyadenylation site is based on CLEAR-CLIP data (Moore et al., 2015). (B) Real-time PCR quantification of mRNAs co-immunoprecipitated with AGO2 (AGO2-RIP). Ret, Vimentin and Ptbp1 are associated with AGO2 in the nucleus of NSC-34 cells in a comparable manner. Average \pm SEM, of data normalized to non-specific IgG isotype control. Two-tailed Student's t-test $\mathrm{p}$-value ${ }^{*} \leq 0.05,{ }^{*} \leq 0.01, * * * 0.001$. Ret $-\mathrm{p}$-value $=0.01343 ;$ Vimentin $-\mathrm{p}$-value $=$ 0.00301; Ptbpl - p-value $=0.03803$. (C) Gel electrophoresis of Ret mRNA isoforms in cytoplasm and nucleus, after AGO2 knockdown (siAGO2) and quantification of isoform densitometry ratio, normalized to control (siNT). Average \pm SEM of 3 repeats, two-tailed Student's t-test (p-value ${ }^{*} \leq 0.05,{ }^{* *} \leq 0.01,{ }^{* *} \leq 0.001$ ). Cytoplasm $-\mathrm{p}$-value $=0.11645$; Nucleus $-p$-value $=0.00689$. (D) Schematic diagram of the bicistronic reporter vector, adapted from (Deng et al., 2018). The vector contains Renilla luciferase protein ORF (hRluc) and firefly luciferase ORF (Luciferase) connected with one IRES, containing at the end of each ORF the proximal or distal PAS of Ret, correspondingly. The relative, activity of the proximal and distal Ret mRNA polyadenylation sites dictates the ratio between the two reporters. (E) AGO2 knockdown (siAGO2) resulted in preference of the distal polyadenylation site. Control reporter, lacking Ret polyadenylation sites (psiCHECK2-IRES), was unchanged. Average $\pm \mathrm{SEM}$ of 5 repeats, two-tailed Student's $t$-test ( $\mathrm{p}$-value $* 0.05, * * \leq 0.01, * * * \leq 0.001$ ). psiCHECK2-Ret $-\mathrm{p}$ value $=0.00378$; psiCHECK2-IRES - p-value $=0.274293748$. (F) Representative micrographs of Ret mRNA smFISH performed on NSC-34 cells previously subjected to AGO2-KD (siAGO2), or control (siNT) treatment $72 \mathrm{hrs}$ before fixation. smFISH was performed to detect only the long Ret variant (cy5, red) or both long and short Ret variants (Alexa 594, green). DAPI - nuclear DNA (blue). (G) Quantification of long and short Ret smFISH signal, 33 images per condition, 3 biological repeats. Average \pm SEM, normalized to controls (siNT). Two-tailed Student's t-test p-value for siAGO2 vs siNT. p-value * $\leq 0.05 ; * * \leq 0.01, * * * \leq 0.001$. Long $/$ Short $-\mathrm{p}$-value $=1.07394 \mathrm{E}-08 ;$ Long $/$ Cell $-\mathrm{p}$-value $=1.20772 \mathrm{E}-09$. 


\section{GDNF signaling is implicated by AGO2-mediated Ret APA-regulation}

Ret mRNA isoforms give rise to RET9 and RET51, which differ in their cterminus (Ibanez, 2013; Rossel et al., 1997), and differentially activate downstream signaling pathways in response to GDNF (Hickey et al., 2009; Lian et al., 2017; TsuiPierchala et al., 2002).

To test whether AGO2-dependent control of Ret mRNA isoform switching is controlling the two protein isoforms, we performed WB analysis on lysates from NSC34 cells, using an antibody that specifically binds to the longer RET51. We demonstrated that knockdown of AGO2 results in $~ 3$-fold increase in the expression of RET51 (Figure 5A, B).

Next, we evaluated the changes in activation, of the GDNF-RET intracellular signaling, following AGO2 knockdown by following the phosphorylation state of AKT (pAKT) in mouse primary motor neurons (De Vita et al., 2000; Hayashi et al., 2000; Ibanez, 2013; Segouffin-Cariou \& Billaud, 2000). WB analysis demonstrated an increase in pAKT in response to GDNF, relative to controls, and AGO2 knockdown resulted in dampening of AKT phosphorylation (Figure 5C, D). Therefore, AGO2 regulates both RET isoform expression and the propagation of GDNF signal into pAKT. Together, we propose that AGO2-dependent control of alternative polyadenylation broadly impacts the neuronal transcriptome and specifically controls the balance between two translated isoforms of the GDNF receptor, RET, affecting intracellular signaling in motor neurons (Figure 5E). 


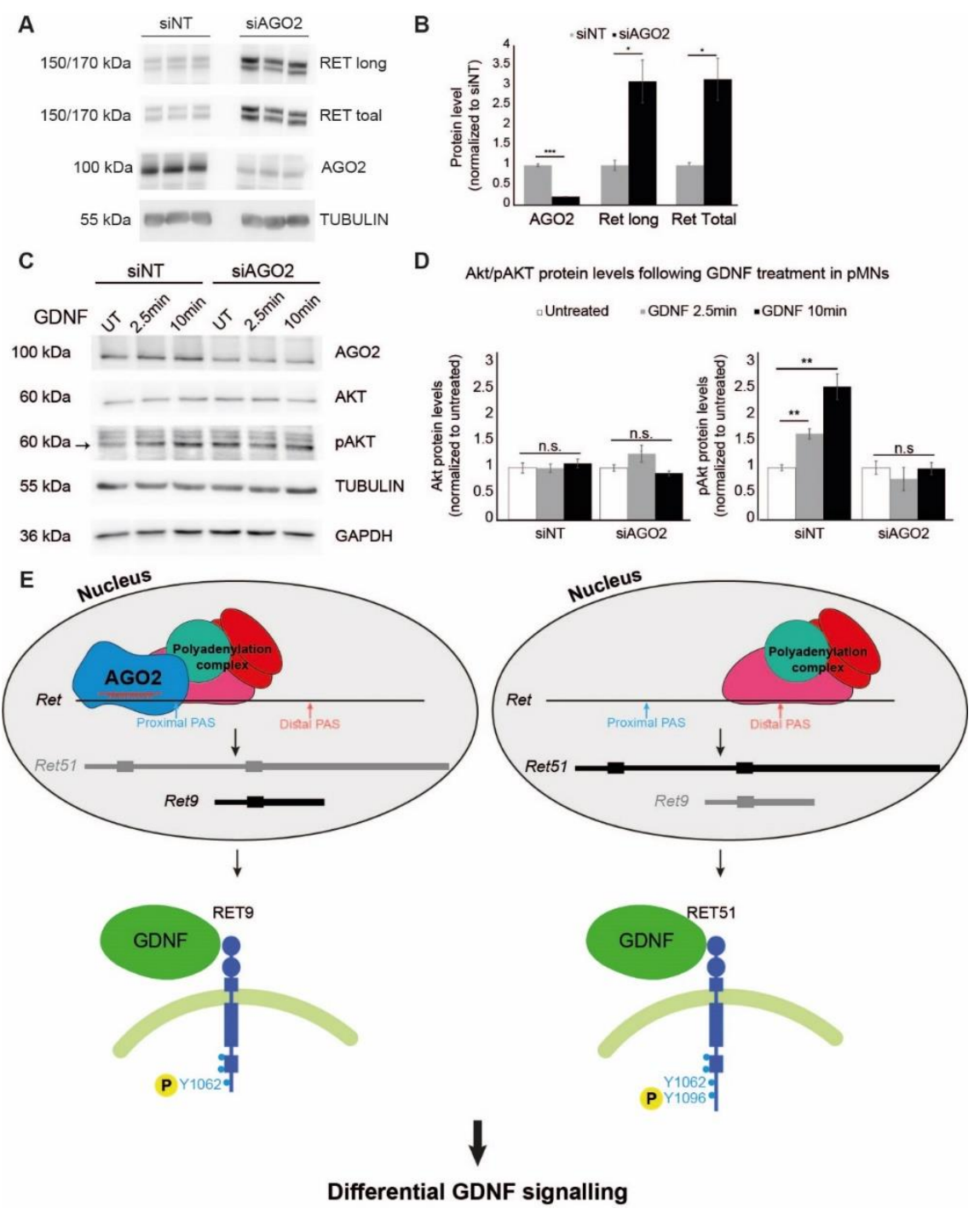

Figure 5. AGO2 controls Ret polyadenylation and GDNF signaling. (A) WB analysis and (B) band densitometry of AGO2 and RET protein isoforms, from NSC-34 cells, treated with siAGO2, normalized to Tubulin and to non-specific siRNA pool as control (siNT). Average \pm SEM based on three biological repeats. Two-tailed Student's t-test p-value $* \leq 0.05 ; * * * \leq 0.001$. AGO2 - p-value $=2.05254 \mathrm{E}-05 ;$ RET long $-\mathrm{p}$-value $=0.01888 ;$ RET total $-\mathrm{p}$-value $=0.01512$. (C) WB analysis of AGO2, AKT, pAKT, Tubulin and GAPDH in primary motor neurons, treated with GDNF for $2.5 \mathrm{~min}$ or $10 \mathrm{~min}$. Representative image of three biological repeats. (D) Band densitometry of Akt and pAkt, normalized to Tubulin/GAPDH and to the untreated control. GDNF induces Akt phosphorylation. AGO knockdown (siAGO2 treatment) abolishes increased Akt phosphorylation. Average \pm SEM based on three biological repeats. Two-tailed Student's t-test $\mathrm{p}$-value $* * \leq 0.01 \mathrm{p}$-values for AKT: siNT - GDNF $2.5 \mathrm{~min}=0.97736$, GDNF $10 \mathrm{~min}=0.53249 ; \mathrm{siAGO} 2-$ GDNF 2.5min $=0.19325$, GDNF 10min $=0.25572$. p-values for pAKT: $\mathrm{siNT}-$ GDNF $2.5 \mathrm{~min}=0.00445$, GDNF 10 $\mathrm{min}=0.00361$; $\mathrm{siAO} 2-$ GDNF $2.5 \mathrm{~min}=$ 0.4527, GDNF 10min $=0.92769$. (E) A model for AGO2-mediated regulation of Ret polyadenylation in neurons. Nuclear AGO2 directs polyadenylation complex at the proximal 
poly(A) site of Ret mRNA, leading to the generation of RET9, whereas the distal polyadenylation site leads to the biogenesis of longer, RET51. RET9 and RET51 differs in signaling downstream of GDNF. 


\section{Discussion}

In this study, we demonstrate that AGO2 is highly abundant in the nucleus of neurons and plays an unexpected role in broadly regulation of alternative polyadenylation. Ret mRNA, which encodes a tyrosine kinase receptor for GDNF, is probably among several mRNAs that are most sensitive to changes in AGO2 levels. Normally, the shorter RET9, is the predominant variant expressed in motor neurons (Lee et al., 2003). However, our data shows that AGO2 contributes to the preference of the short variant, Ret9, by actively controlling polyadenylation. Reduction in the expression of AGO2 changes the balance between the two Ret mRNA isoforms and attenuated intracellular signaling.

AGO2 is the main effector protein of miRNA-mediated silencing and more recently, nuclear AGO2 has been suggested to function in splicing and transcriptional regulation (Ameyar-Zazoua et al., 2012; Benhamed et al., 2012; Sarshad et al., 2018).

Alternative polyadenylation leads to the generation of $3^{\prime}$ mRNA variants (Di Giammartino et al., 2011; Elkon et al., 2013; Fu et al., 2018; Tian \& Manley, 2017) that diversify the transcriptome expressed in the nervous system (Fontes et al., 2017; MacDonald, 2019; Miura et al., 2013; Ulitsky et al., 2012). APA contributes to differential mRNA localization (Mansfield \& Keene, 2012; Taliaferro et al., 2016) and translation (Ainsley et al., 2014; Terenzio et al., 2018). Several RNA-binding proteins have been linked to APA regulation in the nervous system, including TDP-43 (Rot et al., 2017), FUS (Masuda et al., 2015; Schwartz et al., 2012), HnRNPA2/B1 (Martinez et al., 2016) and NOVA (Hwang et al., 2017; Licatalosi et al., 2008; Ule et al., 2003). Mutations in some of these APA regulators are associated with neurodegenerative or neuro-oncological diseases. In one such example, decreased levels of TDP-43, uncovers a cryptic polyadenylation site leading of STMN2 mRNA, which leads to a truncated non-functional STMN2 and eventually to the pathology of ALS (Melamed et al., 2019). Furthermore, global shortening of $3^{\prime}$ UTRs was observed in ALS patients with C9ORF72 G4C2-repeat expansion (Prudencio et al., 2015), the most common genetic cause associated with ALS and frontotemporal dementia.

AGO2 associates with proteins that are directly involved in APA (CSTF1, CPSF2, CPSF3, NUDT21, PABPN1, RBBP6 and PTBP1), or regulate the process 
(ELAVL1, ELAVL2, SRSF3, SRSF7, FUS, TDP-43 and HNRNPA2B1) (AvendanoVazquez et al., 2012; Elkon et al., 2013; Martinez et al., 2016; Rot et al., 2017; Tian \& Manley, 2017). Accordingly, the global shift in polyadenylation preference in response to AGO2 manipulation, suggests that APA regulation is a novel broad function of nuclear AGO2.

RET, the receptor for the neurotrophic factor GDNF, is expressed in the developing and in the mature nervous systems, and is important for axonal growth and synapse development (Baudet et al., 2008; Bonanomi et al., 2012; Enomoto et al., 2001; Gould et al., 2008; Honma et al., 2010; Kramer et al., 2006; Pachnis et al., 1993; Tuttle et al., 2019), including the neuromuscular junction (Baudet et al., 2008). The formation of the short and long versions of RET protein, RET9 and RET51, seems to be the translational consequence of the two alternative mRNA isoforms, downstream of AGO2 activity. The balance between RET51 and RET9 determines the signaling output once activated downstream of GDNF (Besset et al., 2000; Coulpier et al., 2002; Crowder et al., 2004; Grimm et al., 2001; Hayashi et al., 2000; Lundgren et al., 2006; Perrinjaquet et al., 2010; Richardson et al., 2012; Segouffin-Cariou \& Billaud, 2000; Tsui \& Pierchala, 2010). We suggest that continuous AGO2 activity is required for maintaining RET9 predominance in motor neurons (Lee et al., 2003) which is needed for motor neuron survival (Airaksinen \& Saarma, 2002).

It was previously shown that GDNF acts differently on motor neuron axons, facilitating growth and muscle innervation at axon terminals and survival pathways in the soma (Zahavi et al., 2015), which may be associated with differential Ret isoform distribution along the neuron.

Finally, the relevance of $\mathrm{AGO} 2$ to neurons and neurodegenerative diseases, including ALS, underscores the motivation to explore AGO2 neuronal functions but requires further studies to be elucidated.

Limitations: The abundance of $\mathrm{AGO} 2$ in the nucleus of neurons may be responsible for its involvement in APA. Therefore, we cannot rule out that in other cell types APA is also regulated by AGO. Furthermore, while direct AGO2 interactors are APA regulators, some of the effects may be indirect, for example by miRNA-based silencing of APA factor expression in the cytoplasm. 


\section{Materials and Methods}

\section{Cell culture and induction of cellular stress}

NSC-34 cells (Cashman et al., 1992) were cultured in Dulbecco's Modified Eagle Medium (DMEM, Biological Industries, 01-050-1A) supplemented with 10\% Fetal Bovine Serum (FBS, Biological Industries, 04-001-1A), 1\% penicillin-streptomycin (Pen-Strep, Biological Industries, 03-031-1B) and 1\% L-glutamine (Biological Industries, 03-020-1B). Cells were grown at $37^{\circ} \mathrm{C}, 5 \% \mathrm{CO}_{2}$. N2A cells were cultured in DMEM supplemented with $10 \%$ FBS and $1 \%$ Pen-Strep. Cells were grown at $37^{\circ} \mathrm{C}$, $5 \% \mathrm{CO}_{2}$.

\section{Culture of primary motor neurons}

All experiments were performed in accordance with relevant guidelines and regulations of the Institutional Animal Care and Use Committee at Weizmann Institute of Science. Primary motor neurons (pMNs) were isolated and cultured as previously described (Milligan \& Gifondorwa, 2011). Briefly, wild type (WT) ICR timed-pregnant females were sacrificed at mouse embryonic day 13.5 (E13.5), and spinal cords were dissected from embryos and dissociated enzymatically with papain $(2 \mathrm{mg} / \mathrm{ml}$, Sigma, P4762). Motor neurons were separated over a gradient of Optiprep (Sigma, D1556) and plated on tissue culture plates pre-coated with $3 \mu \mathrm{g} / \mathrm{ml}$ poly-Lysine (Sigma, P4707) and $3 \mu \mathrm{g} / \mathrm{ml}$ laminin (Gibco, 23017015). Motor neurons were cultured with Neurobasal medium (Gibco, 211030-49) supplemented with 2\% B27 (Gibco, 17504-044) 2\% horse serum (Sigma), X1 Glutamax (Gibco, 35050-061), gentamycin $1 \mu \mathrm{g} / \mathrm{ml}$ (Sigma, G1272) and 1ng/ml CNTF (Peprotech, 450-50-25) and GDNF (Peprotech, 450-51-10). For GDNF treatment assay, cells were changed to starvation medium (Neaurobasal medium with antibiotics only) for $16 \mathrm{hrs}$, then treated with $100 \mathrm{ng} / \mathrm{ml}$ GDNF for $2.5 \mathrm{~min}$ and $10 \mathrm{~min}$.

\section{Whole cell lysates and subcellular fractions}

The protocol was adjusted to neuronal cells by harvesting cells using a low detergentconcentration lysis buffer supplemented with protease inhibitors and phosphatase inhibitors. One confluent $15 \mathrm{~cm}$ NSC-34 culture dish was used per experimental repeat. Cells were washed ice-cold PBS prior to nuclear and cytosolic fractionation. All buffers used were prepared on the same day and supplemented with Protease Inhibitor Cocktail (Roche, 04693132001) and Phosphatase Inhibitor Cocktail (Roche, 04906837001). For WCL preparation, cells were harvested in ice-cold RIPA [50mM Tris-HCl, pH 7.5, 
$150 \mathrm{mM} \mathrm{NaCl}, 1 \% \mathrm{NP}-40,0.5 \%$ deoxycholate (DOC), $0.1 \%$ SDS] and thoroughly mixed by vortex. The supernatant was collected after 10min incubation on ice, and 10 min centrifugation at $15,871 \mathrm{xg}, 4^{\circ} \mathrm{C}$. For nuclear and cytosolic fractionation, cells were harvested in ice-cold Lysis Buffer A [10mM Tris-HCl, pH 7.5, 10mM NaCl, 3mM $\mathrm{MgCl} 2,0.5 \% \mathrm{NP}-40]$, incubated for $10 \mathrm{~min}$ on ice while vortexing every other minute. The cytoplasmic fraction was the collected supernatant after centrifugation for $10 \mathrm{~min}$ at $15,871 \mathrm{xg}, 4^{\circ} \mathrm{C}$. The nuclei were further pelleted, washed three times with ice-cold lysis buffer $\mathrm{A}$ by pipetting and then centrifuged for $10 \mathrm{~min}$ at $15,871 \mathrm{xg}, 4^{\circ} \mathrm{C}$. To gain the nuclear fraction, nuclei were resuspended in ice-cold RIPA, sonicated on ice at $30 \%$ power for three cycles of $10 \mathrm{sec}$ with $20 \mathrm{sec}$ intervals and centrifuged for $10 \mathrm{~min}$ at $15,871 \mathrm{xg}, 4^{\circ} \mathrm{C}$. The supernatant collected at this step was defined as the nuclear fraction. Protein concentrations were determined using Bio-Rad Protein Assay Dye Reagent (Bio-Rad, 500-0006). Fresh extracts were used for immunoprecipitation (IP) experiments, mass spectrometry (MS) or Western Blot (WB) analysis.

\section{Immunoprecipitation}

$50 \mu 1$ of Dynabeads Protein G (Novex by Life Technologies, 10004D) were mixed with $5 \mu \mathrm{g}$ of antibody (mouse-anti-AGO2; or mouse-IgG-isotype control), diluted in $200 \mu \mathrm{l}$ PBS $+0.1 \%$ TWEEN-20 (0.1\% PBST) per sample, incubated by tilting at room temperature (RT) for $10 \mathrm{~min}$ and washed three times with $0.1 \%$ PBST. Then, $300 \mu 1$ of protein extract $(\sim 1.5 \mathrm{mg}$ protein) was added to the bead-antibody complexes and incubated with rotation over-night (O.N.) at $4^{\circ} \mathrm{C}$. For RNase treated samples, protein lysate was treated with RNase A/T1 (Thermo Scientific, EN0551, 18 $\mu$ g RNase A and $45 \mathrm{U}$ of RNase $\mathrm{T} 1$ ) for $30 \mathrm{~min}$ at $37^{\circ}$ with tilt prior to incubation with the antibody-beads complex. The following day, beads-antibody-antigen complexes were washed three times with PBS, resuspended in $150 \mu \mathrm{PBS}$ and stored at $-80^{\circ} \mathrm{C}$ until further analysis. For AGO2-RNA-Immunoprecipitation (AGO2-RIP), 25\% of the precipitate was used for protein analysis, and 75\% for RNA extraction, and was stored in $700 \mu 1$ QIAzol Lysis Reagent (Qiagen, 79306) until RNA purification step.

\section{Western blot}

Cell extracts or IP-purified proteins were denatured by boiling $\left(95^{\circ} \mathrm{C}\right)$ in $\mathrm{X} 5$ sample buffer (60mM Tris-HCl pH 6.8, 25\% glycerol, 2\% SDS, 14.4mM $\beta$-mercaptoethanol, $0.1 \%$ bromophenol blue) for $5 \mathrm{~min}$ and resolved by $8 \%-10 \%$ SDS-PAGE, $100-120 \mathrm{~V}$, 
70min. Proteins were transferred to a nitrocellulose membrane (Whatmann, 10401383) at $250 \mathrm{~mA}, 70 \mathrm{~min}$. Membranes were stained with Ponceau (Sigma-Aldrich, P7170) to assess transfer quality, blocked for 1 hour at RT with $5 \%$ milk protein in PBS $+0.05 \%$ TWEEN-20 (0.05\% PBST) and incubated, rocking, with primary antibodies O.N. at $4{ }^{\circ} \mathrm{C}$ in Antibody-Solution [5\% Bovine Serum Albumin, 0.02\% sodium azide, 5 drops of phenol red in $0.05 \%$ PBST]. Following primary antibody incubation, membranes were washed three times for $5 \mathrm{~min}$ at RT with $0.05 \%$ PBST and incubated for 1 hour at RT with horseradish peroxidase (HRP)-conjugated species-specific secondary antibodies. Membranes were washed three times for $5 \min$ in $0.05 \%$ PBST at RT and protein bands were subsequently visualized by ImageQuant ${ }^{\mathrm{TM}}$ LAS 4000 (GE Healthcare Life Sciences) using EZ-ECL Chemiluminescence detection kit for HRP (Biological Industries, 20-500-120).

\section{Affinity Purification coupled to Mass Spectrometry proteomics (AP-MS)}

Study design for the identification of AGO2-interacting proteins included four independent biological repeats, in each NSC-34 cell lysate from four confluent $10 \mathrm{~cm}$ culture plates. Immunoprecipitated samples were subjected to AP-MS. Quantification was performed using MS1 based, label-free quantification (Shalit et al., 2015). The mass spectrometry proteomics data have been deposited to the ProteomeXchange Consortium (Deutsch et al., 2020) via the PRIDE (Perez-Riverol et al., 2019) partner repository with the dataset identifier PXD023112.

Sample preparation: For whole lysates samples were subjected to in-solution tryptic digestion using the suspension trapping (S-trap) as previously described (Elinger et al., 2019). Briefly, $50 \mathrm{ug}$ of total protein was reduced with $5 \mathrm{mM}$ dithiothreitol and alkylated with $10 \mathrm{mM}$ iodoacetamide in the dark. Each sample was loaded onto S-Trap microcolumns (Protifi, USA) according to the manufacturer's instructions. After loading, samples were washed with 90:10\% methanol/50 mM ammonium bicarbonate. Samples were then digested with trypsin (1:50 trypsin/protein) for $1.5 \mathrm{~h}$ at $47^{\circ} \mathrm{C}$. The digested peptides were eluted using $50 \mathrm{mM}$ ammonium bicarbonate. Trypsin was added to this fraction and incubated overnight at $37^{\circ} \mathrm{C}$. Two more elutions were made using $0.2 \%$ formic acid and $0.2 \%$ formic acid in $50 \%$ acetonitrile. The three elutions were pooled together and vacuum-centrifuged to dryness. Samples were kept at $-80^{\circ} \mathrm{C}$ until further analysis. 
For AGO2-IP, samples were subjected to on-bead tryptic digestion. Proteins were first reduced by incubation with dithiothreitol $\left(5 \mathrm{mM}\right.$; Sigma-Aldrich) for $30 \mathrm{~min}$ at $60^{\circ} \mathrm{C}$, and alkylated with $10 \mathrm{mM}$ iodoacetamide (Sigma-Aldrich) in the dark for $30 \mathrm{~min}$ at $21^{\circ} \mathrm{C}$. Proteins were then subjected to trypsin digestion (Promega; Madison, WI, USA) at trypsin:protein ratio of $1: 50$ at $37^{\circ} \mathrm{C}$. Digestion was inhibited with trifluroacetic acid $(1 \%)$ after $16 \mathrm{~h}$, supernatant was isolated, desalted using solid-phase extraction columns (Oasis HLB, Waters, Milford, MA, USA) and stored in $-80^{\circ} \mathrm{C}$ until further analysis.

Liquid chromatography: ULC/MS grade solvents were used for all chromatographic steps. For whole lysates, dry digested samples were dissolved in 97:3\% $\mathrm{H}_{2} \mathrm{O}$ /acetonitrile $+0.1 \%$ formic acid. For all smaples (whole lysates and AGO2-IP), each sample was loaded using split-less nano-Ultra Performance Liquid Chromatography (10 kpsi nanoAcquity; Waters, Milford, MA, USA). The mobile phase was: A) $\mathrm{H}_{2} \mathrm{O}+0.1 \%$ formic acid and $\mathrm{B}$ ) acetonitrile $+0.1 \%$ formic acid. Desalting of the samples was performed online, using a Symmetry C18 reversed-phase trapping column $(180 \mu \mathrm{m}$ internal diameter, $20 \mathrm{~mm}$ length, $5 \mu \mathrm{m}$ particle size; Waters $)$. The peptides were then separated using a T3 HSS nano-column $(75 \mu \mathrm{m}$ internal diameter, $250 \mathrm{~mm}$ length, $1.8 \mu \mathrm{m}$ particle size; Waters) at $0.35 \mu \mathrm{L} / \mathrm{min}$. Peptides were eluted from the column into the mass spectrometer using the following gradient: whole lysates - $\%$ to $20 \% \mathrm{~B}$ in $135 \mathrm{~min}, 20 \%-30 \%$ in $17 \mathrm{~min}, 30 \%$ to $90 \% \mathrm{~B}$ in $10 \mathrm{~min}$, maintained at $90 \%$ for $5 \mathrm{~min}$ and then back to initial conditions; AGO2-IP - 4\% to $30 \% \mathrm{~B}$ in $50 \mathrm{~min}, 30 \%$ to $90 \% \mathrm{~B}$ in $5 \mathrm{~min}$, maintained at $90 \%$ for $5 \mathrm{~min}$ and then back to initial conditions.

Mass Spectrometry: For whole lysates - The nanoUPLC was coupled online through a nanoESI emitter (10 $\mu \mathrm{m}$ tip; New Objective; Woburn, MA, USA) to a Orbitrap Fusion Lumos mass spectrometer (Thermo Scientific) using a FlexIon nanospray apparatus (Proxeon). Data was acquired in data dependent acquisition (DDA) mode, using a 3second cycle time method. MS1 resolution was set to 120,000 (at $200 \mathrm{~m} / \mathrm{z}$ ) in the Orbitrap, mass range of 300-2000m/z, AGC of $4 \mathrm{e} 5$ and maximum injection time was set to $50 \mathrm{msec}$. MS2 was performed in the ion trap, quadrupole isolation $1 \mathrm{~m} / \mathrm{z}$, AGC of 1e4, dynamic exclusion of $30 \mathrm{sec}$ and maximum injection time of $50 \mathrm{msec}$.

For AGO2-IP - The nanoUPLC was coupled online through a nanoESI emitter $(10 \mu \mathrm{m}$ tip; New Objective; Woburn, MA, USA) to a quadruple orbitrap mass spectrometer (Q Exactive Plus, Thermo Fisher Scientific) using a FlexIon nanospray apparatus 
(Proxeon). Data was acquired in DDA mode, using a Top10 method. MS1 resolution was set to $70,000($ at $200 \mathrm{~m} / \mathrm{z}$ ) and maximum injection time was set to $60 \mathrm{msec}$, automatic gain control (AGC) target of $3 \mathrm{e} 6$. MS2 resolution was set to 17,500 and maximum injection time of $60 \mathrm{msec}$, AGC target of 1e5. Quadrupole isolation window was set to $1.7 \mathrm{~m} / \mathrm{z}$.

Raw Data processing: Raw data was processed with MaxQuant v1.6.0.16 (Cox \& Mann, 2008), searched with the Andromeda against mouse (mus musculus) protein database as downloaded from Uniprot (www.uniprot.com) and appended with common lab protein contaminants. Enzyme specificity was set to trypsin and up to two missed cleavages were allowed. Fixed modification was set to carbamidomethylation of cysteines and variable modifications were set to oxidation of methionines, and deamidation of glutamines and asparagines. Peptide precursor ions were searched with a maximum mass deviation of $4.5 \mathrm{ppm}$ and fragment ions with a maximum mass deviation of $20 \mathrm{ppm}$. Peptide and protein identifications were filtered at an FDR of 1\% using the decoy database strategy (MaxQuant's "Revert" module). The minimal peptide length was 7 amino-acids and the minimum Andromeda score for modified peptides was 40. Peptide identifications were propagated across samples using the matchbetween-runs option checked. Searches were performed with the label-free quantification (LFQ) option selected.

Proteomics Statistical Analysis: ProteinGroups output table was imported from MaxQuant to Perseus environment v1.6.0.2 (Tyanova et al., 2016). Quality control excluded reverse proteins, proteins identified by a single peptide, and contaminants. For lysate input analysis, quantitative comparisons were calculated based on log2transformed LFQ values. Protein groups required $\geq 3$ valid values/group. Missing data were replaced using imputation, assuming normal distribution with a downshift of 1.6 standard deviations and a width of 0.4 of the original ratio distribution. Student's t-test with $\mathrm{S} 0=0.1$ was performed with FDR $p$-value $\leq 0.05$ for pairs of cytoplasmic fraction and nuclear fraction samples in each condition.

For AGO2-pull down analysis, non-specific IgG-isotype control binders were excluded by $\log 2$-transformed LFQ values. Protein groups required $\geq 3$ valid values/group. Missing data were replaced using imputation, assuming normal distribution with a downshift of 1.6 standard deviations and a width of 0.4 of the original ratio distribution. 
Enriched AGO2 interactors were called by Student's t-test (AGO2-IP vs corresponding IgG-control) with $\mathrm{S} 0=0.1$ and FDR $p$-value $\leq 0.05$ and fold-change threshold of 2 -fold enrichment.-

\section{Immunofluorescence}

NSC-34 cells were seeded at a density of 75,000 cells $/ \mathrm{cm}^{2}$ on $13 \mathrm{~mm}$ glass cover-slips (Thermo Fisher Scientific), precoated with $0.002 \%$ poly-L-lysine (Sigma-Aldrich, P4707) and cultured for 2 days at $37^{\circ} \mathrm{C}$ and $5 \% \mathrm{CO}_{2}$. pMNs were seeded 200,000 cells per coverslip, precoated as described. Cells were then washed with PBS, fixed with $4 \%$ paraformaldehyde (PFA) for $15 \mathrm{~min}$ at RT, permeabilized with PBS containing $0.2 \%$ (vol/vol) Triton X-100 and blocked using CAS block (Invitrogen, 008-120) for 10min at RT. After incubation with primary antibodies O.N., $4^{\circ} \mathrm{C}$, cells underwent three washes with PBS (5min each) and incubated for 1 hour at RT with secondary antibodies conjugated with $\mathrm{Cy} 2, \mathrm{Cy} 3$ or $\mathrm{Cy} 5$ diluted in $\mathrm{CAS}$ block. Glass cover slips were mounted on Superfrost microscope slides (Thermo Fisher Scientific) with Fluoroshield mounting media containing DAPI (Sigma-Aldrich, F6057). Fluorescence images were captured using a Zeiss LSM780/800 Laser Scanning confocal microscope system.

\section{SiRNA knockdown}

Dharmacon siGenome SMARTpool siRNAs against mouse AGO2 (M-058989-010005) was used at a final concentration of 20nM to knockdown AGO2 in NSC-34 cells, N2A cells or primary MNs. siRNAs were transfected into NSC-34 or N2A cells using Lipofectamine RNAiMAX Reagent (Thermo Fisher Scientific, 13778-075) according to the manufacturer's instructions. For pMNs, Dharmafect 4 (Dharmacon, T-2004-02) reagent was used for siRNA transfection. Dharmacon siGENOME Non-targeting pool \#2 (siNT, D-001206-14-05) were used as controls. Knockdown efficiency was assessed by RNA extraction followed by quantitative Real-time PCR (qRT-PCR).

\section{Quantitative Real-time PCR}

Total RNA from cultured NSC-34 cells or primary motor neurons was isolated using DirectZole RNA Purification Kit (Zymo Research, R2052), and reverse transcribed using qScript cDNA Synthesis Kit (Quanta Biosciences, 95047-100). Quantitative realtime PCR was performed using StepOnePlus real-time PCR instrument (Applied Biosystems), in $>3$ independent biological repeats and technical duplicates. KAPA SYBR FAST ABI Prism (KAPA Biosystems, KK4604) was used for detection of 
mRNAs. Gapdh or TBP were used as reference genes for normalization of expression levels. Statistical analysis was performed using Student's t-test. For AGO2-RIP experiments, RNA was extracted using miRNeasy micro Kit (Qiagen, 217084), and reverse transcribed using the miScript II RT Kit (Qiagen, 218161). Quantitative realtime PCR was performed using StepOnePlus real-time PCR instrument, in $>3$ independent biological repeats and technical duplicates. miScript SYBR Green PCR (Qiagen, 218073) and KAPA SYBR FAST ABI Prism kits were used for detection of miRNAs and mRNAs respectively. $U 6$ and $T B P$ were used as reference genes for normalization of miRNA and mRNA levels, respectively. All primer sequences are described in Supplementary Table 1.

\section{3'-RNA sequencing}

cDNA Libraries Preparation: The poly(A)seq cDNA libraries were generated using the reverse QuantSeq 3' mRNA-seq Library Prep Kit for Illumina (Lexogen). Libraries were prepared from 400ng of total RNA according to kit instructions. Single-end sequencing (60bp) was performed on Illumina HiSeq2500 with a Rapid Run flow-cell. RNA-seq data are available in the ArrayExpress (Athar et al., 2019) database (http://www.ebi.ac.uk/arrayexpress) under accession number E-MTAB-9907.

Data Processing: Bioinformatic analysis pipeline was performed as described in (Rot et al., 2017). Briefly, all data sets were processed by aligning the reads to the reference mouse genome (mm10) using STAR aligner (Dobin et al., 2013) with default parameters and with the GTF annotations from Ensembl. The polyadenylation events were determined by tagging only one position per alignment (the first $5^{\prime}$ aligned nucleotide). Alignments containing stretches of six consecutive A or with $70 \% \mathrm{~A}$ coverage in any 10-nt sub-window in the region [-10..10] surrounding the polyadenylation events were filtered out. Polyadenylation events were ranked by read count in descending order and only the high-ranking events that are more than $125 \mathrm{nt}$ apart were considered as dominant poly(A) sites and therefore in the analysis. This resulted in the global poly(A) site database. To allow variation in cleavage precision, the per-experiment expression of each poly(A) site was computed by summing the read counts that identify any position in the region $[-5 . .5]$ surrounding the polyA cleavage sites. 
Statistical Analysis: DEXSeq algorithm was applied to identify regulated poly(A) sites in genes. Count values of all poly(A) sites remaining after filtering for all replicates for control and AGO2-KD 3'end sequencing experiments were input. The output was foldchange $(\log 2)$ and FDR adjusted p-value for each site. Genes in which no poly(A) site reached significance $(\mathrm{p} \leq 0.05)$ were classified as controls. In regulated genes with more than one poly(A) site, only two significantly changed sites (adjusted p-value $\leq 0.05$ ) with highest difference in fold change were selected for each gene, additionally requiring that fold changes are of opposite direction. If a proximal site had fold change $<0$, the site was marked as repressed, and if fold change $>0$, marked as enhanced (the reverse holds for distal sites). In control genes, the two poly(A) sites with highest read count were considered for further analysis; the proximal and distal control poly(A) sites were further labeled as control-down and control-up (dependent on their fold change). The poly(A) site pairs were further classified into different types of alternative polyadenylation (same exon, composite exon, and skipped exon (Rot et al., 2017)), using the gene level annotation which was computed by linearizing the Ensembl gene annotation by merging the transcript annotation.

\section{Semi-quantitative PCR-based Alternative polyadenylation assay (3'RACE-like)}

RNA was extracted from the cells using DirectZole RNA MiniPrep (Zymo Reseach, R2052) according to kit instructions. cDNA was produced from 500ng of RNA using the high-capacity reverse transcription kit (Applied Biosystems, 4374966), and Oligo(dT)-VN primers with an adapter sequence according to the manufacturers' instructions. To evaluate alternative polyadenylation (APA) events, a semi-quantitative RT-PCR reaction was performed using Q5 Hot Start High-Fidelity DNA polymerase (NEB, M0493S) in a LabCycler thermocycler (SensoQuest). 5ng cDNA was used for PCR and amplified using 29 cycles. RT-PCR products were separated on $1.5 \%$ agarose gel and visualized using MiniBIS Pro (DNR Bio-Imaging Systems). Quantification of APA band intensities were determined using ImageJ software and an average of three biological replicates was plotted. Forward primers for each gene were designed to be in the last exon or one upstream. Reverse primer was designed for the adapter sequence used in the cDNA generation step. All primers are listed in Supplementary Table 1. 


\section{Single-molecule Fluorescent in-situ Hybridization (smFISH)}

Probe library construction, hybridization procedure and imaging conditions were previously described (Farack et al., 2019; Itzkovitz \& van Oudenaarden, 2011; Lyubimova et al., 2013; Raj et al., 2008). Probe libraries were designed using the Stellaris FISH Probe Designer (Biosearch Technologies) and consisted of 41-48 probes each of length $20 \mathrm{bps}$, complementary to the mRNA sequence of either both Ret variants (Ret-all, Ret9, Ret51), or a unique sequence in the long Ret variant (Ret-long, Ret51). Ret-all probe library was coupled to Alexa594 (CAL Fluor Red 610, Stellaris, Biosearch Technologies); Ret-long probe library was coupled to Cy5 (Quasar 670, Stellaris Biosearch Technologies). NSC-34 cells were seeded 500,000 cells per coverslip on $22 \times 22 \mathrm{~mm}$ glass coverslips (Thermo Fisher Scientific), coated with $0.002 \%$ poly-L-lysine (Sigma-Aldrich, P4707). pMNs were seeded 500,000 cells per coverslip, precoated as described. Cells were transfected with siAGO2 or siNT (as described) and cultured for $72 \mathrm{hrs}$ at $37^{\circ} \mathrm{C}$ and $5 \% \mathrm{CO}_{2}$. Cells were then washed with nuclease-free PBS, fixed with $4 \%$ paraformaldehyde (PFA) for 10min at RT, washed again with PBS and incubated in $70 \%$ ethanol for $1-3$ days at $4{ }^{\circ} \mathrm{C}$. Formamide concentration of the washing and hybridization buffers was $25 \%$. Fixed cells were washed twice in 2xSSC, then incubated for $1.5 \mathrm{hrs}$ with the washing buffer before hybridizing with the probe libraries. Probes were diluted in hybridization buffer and cells were incubated O.N. at $30^{\circ} \mathrm{C}$. The following day, cells were washed twice with washing buffer for $30 \mathrm{~min}$ at $30^{\circ} \mathrm{C}$. Next, cells were washed with GLOX buffer ( $2 x \mathrm{SSC}, 10 \%$ glucose, $10 \mathrm{mM}$ Tris) for 5min at RT. Nuclei were stained with DAPI (Sigma-Aldrich, D9542), then washed again with GLOX buffer twice, 5min each wash. Slides were mounted using ProLong Gold (Molecular Probes, P36934).

Imaging: smFISH imaging was performed using a Nikon-Ti2 Eclipse inverted fluorescence microscope equipped with a 100×0il-immersion objective and a Photometrics iXon Ultra 888 EMCCD camera using NIS-Elements Advance Research software (Nikon Instruments Inc.). Quantification was performed on stacks of optical sections with $\mathrm{Z}$ spacing of $0.3 \mu \mathrm{m}$.

Image Analysis, quantification and statistics: Imaris Cell Imaging Software 9.2.1 (Oxford Instruments Group), was used to analyze images, including detection and quantification of smFISH signal of each probe and colocalization of the signals from 
both probes. Cell number for each image was calculated based on DAPI signal using ImageJ v1.52n (Schindelin et al., 2012) software for per-cell quantification. Images were visualized and processed using ImageJ v1.52. Statistical analysis was performed using Student's t-test.

\section{Cloning of APA reporter vector}

Construction of the Luciferase-based APA reporter vector was performed based on (Deng et al., 2018) using Restriction-Free Cloning (Unger et al., 2010) upon the psiCHECK-2 dual luciferase assay vector. All amplification reactions were performed using Q5 Hot Start High-Fidelity DNA polymerase (NEB, M0493S) in a LabCycler thermocycler (SensoQuest). The HSV-TK promoter was replaced with IRES sequence to allow the transcription of a bicistronic mRNA. The vector created following this step was used as control (psiCHECK-2-IRES). For evaluation of Ret APA (psiCHECK-2Ret), the generic poly(A) signal at the end of the first ORF was replaced with Ret proximal poly(A) site and with Ret distal poly(A) site for the second ORF (cleavage site $+/-200 \mathrm{bps}$ for each poly(A) site). All vectors were verified by sequencing. Primers used for cloning are listed in Supplementary Table 2.

\section{Dual Luciferase Activity Assay Hela}

N2A cells were co-transfected using Lipofectamine 2000 Transfection Reagent (Thermo Fisher Scientific, 11668019) with either the control luciferase vector (psiCHECK-2-IRES) or Ret construct (psiCHECK-2-Ret), combined with either siAGO2 or siNT. Cells were harvested $72 \mathrm{hrs}$ post-transfection. The resulting lysates were used to measure the humanized renilla (hRluc) and firefly (hluc) luciferase activities with the Dual-Luciferase Reporter Assay kit (Promega, E1960) according to the manufacturer's instructions. Luminesce was read using Veritas luminometer (Turner BioSystems, CA, USA). Statistical analysis was performed using Student's ttest for 5 replicates for each condition.

\section{Antibodies}

All Antibodies used in this study are listed in Supplementary Table 3. 


\section{Acknowledgements}

E.H. is the Mondry Family Professorial Chair and head of the Nella and Leon Benoziyo Center for Neurological Diseases at Weizmann Institute of Science. We thank Topaz Altman and Eran Perlson (Tel Aviv University) for discussions and reagents, members of the Hornstein lab for helpful critiques. Research in the Hornstein lab was supported by the Radala Foundation the Minerva Foundation with funding from the Federal German Ministry for Education and Research, ISF Legacy grant 828/ 17; Target ALS (118945); the European Research Council European Union's Seventh Framework Programme (FP7/2007-2013)/ERC grant agreement 617351; Israel Science Foundation (135/16, 392/21); the ALS Therapy Alliance; AFM-Te' le' thon (20576); the Motor Neurone Disease Association (UK); The Thierry Latran Foundation for ALS Research; ERA-Net Research Programme on Rare Diseases (FP7); Yeda-Sela, Yeda-CEO; the Israel Ministry of Trade and Industry; Y. Leon Benoziyo Institute for Molecular Medicine; the Benoziyo Center Neurological Disease; the Kekst Family Institute for Medical Genetics; the David and Fela Shapell Family Center for Genetic Disorders Research; the Crown Human Genome Center; the Nathan, Shirley, Philip, and Charlene Vener New Scientist Fund; the Julius and Ray Charlestein Foundation; the Fraida Foundation; the Wolfson Family Charitable Trust; the Abney Foundation; Merck; Maria Halphen; and the estates of Fannie Sherr, Lola Asseof, Lilly Fulop, and . Edward and Janie Moravitz. 
bioRxiv preprint doi: https://doi.org/10.1101/2020.12.15.422806; this version posted December 15, 2020. The copyright holder for this preprint (which was not certified by peer review) is the author/funder. All rights reserved. No reuse allowed without permission.

\section{Declaration of Interests}

The authors declare no competing interests. 


\section{References}

Ainsley, J. A., Drane, L., Jacobs, J., Kittelberger, K. A., \& Reijmers, L. G. (2014). Functionally diverse dendritic mRNAs rapidly associate with ribosomes following a novel experience. Nat Commun, 5, 4510. https://doi.org/10.1038/ncomms5510

Airaksinen, M. S., \& Saarma, M. (2002). The GDNF family: signalling, biological functions and therapeutic value. Nat Rev Neurosci, 3(5), 383-394. https://doi.org/10.1038/nrn812

Ameyar-Zazoua, M., Rachez, C., Souidi, M., Robin, P., Fritsch, L., Young, R., Morozova, N., Fenouil, R., Descostes, N., Andrau, J. C., Mathieu, J., Hamiche, A., Ait-Si-Ali, S., Muchardt, C., Batsche, E., \& Harel-Bellan, A. (2012). Argonaute proteins couple chromatin silencing to alternative splicing. Nat Struct Mol Biol, 19(10), 998-1004. https://doi.org/10.1038/nsmb.2373

Arce, V., Pollock, R. A., Philippe, J. M., Pennica, D., Henderson, C. E., \& deLapeyriere, O. (1998). Synergistic effects of schwann- and muscle-derived factors on motoneuron survival involve GDNF and cardiotrophin-1 (CT-1). $J$ Neurosci, 18(4), 1440-1448. http://www.ncbi.nlm.nih.gov/pubmed/9454853

Athar, A., Fullgrabe, A., George, N., Iqbal, H., Huerta, L., Ali, A., Snow, C., Fonseca, N. A., Petryszak, R., Papatheodorou, I., Sarkans, U., \& Brazma, A. (2019). ArrayExpress update - from bulk to single-cell expression data. Nucleic Acids Res, 47(D1), D711-D715. https://doi.org/10.1093/nar/gky964

Avendano-Vazquez, S. E., Dhir, A., Bembich, S., Buratti, E., Proudfoot, N., \& Baralle, F. E. (2012). Autoregulation of TDP-43 mRNA levels involves interplay between transcription, splicing, and alternative polyA site selection. Genes Dev, 26(15), 1679-1684. https://doi.org/10.1101/gad.194829.112

Bartel, D. P. (2004). MicroRNAs: genomics, biogenesis, mechanism, and function. Cell, 116(2), 281-297. http://www.ncbi.nlm.nih.gov/pubmed/14744438

Baudet, C., Pozas, E., Adameyko, I., Andersson, E., Ericson, J., \& Ernfors, P. (2008). Retrograde signaling onto Ret during motor nerve terminal maturation. $J$ Neurosci, 28(4), 963-975. https://doi.org/10.1523/JNEUROSCI.4489-07.2008

Benhamed, M., Herbig, U., Ye, T., Dejean, A., \& Bischof, O. (2012). Senescence is an endogenous trigger for microRNA-directed transcriptional gene silencing in human cells. Nat Cell Biol, 14(3), 266-275. https://doi.org/10.1038/ncb2443

Besset, V., Scott, R. P., \& Ibanez, C. F. (2000). Signaling complexes and proteinprotein interactions involved in the activation of the Ras and phosphatidylinositol 3-kinase pathways by the c-Ret receptor tyrosine kinase. $J$ Biol Chem, 275(50), 39159-39166. https://doi.org/10.1074/jbc.M006908200

Bonanomi, D., Chivatakarn, O., Bai, G., Abdesselem, H., Lettieri, K., Marquardt, T., Pierchala, B. A., \& Pfaff, S. L. (2012). Ret is a multifunctional coreceptor that integrates diffusible- and contact-axon guidance signals. Cell, 148(3), 568-582. https://doi.org/10.1016/j.cell.2012.01.024

Bottini, S., Hamouda-Tekaya, N., Mategot, R., Zaragosi, L. E., Audebert, S., Pisano, S., Grandjean, V., Mauduit, C., Benahmed, M., Barbry, P., Repetto, E., \& Trabucchi, M. (2017). Post-transcriptional gene silencing mediated by microRNAs is controlled by nucleoplasmic Sfpq. Nat Commun, 8(1), 1189. https://doi.org/10.1038/s41467-017-01126-X 
Carter, M. T., Yome, J. L., Marcil, M. N., Martin, C. A., Vanhorne, J. B., \& Mulligan, L. M. (2001). Conservation of RET proto-oncogene splicing variants and implications for RET isoform function. Cytogenet Cell Genet, 95(3-4), 169-176. https://doi.org/10.1159/000059341

Cashman, N. R., Durham, H. D., Blusztajn, J. K., Oda, K., Tabira, T., Shaw, I. T., Dahrouge, S., \& Antel, J. P. (1992). Neuroblastoma x spinal cord (NSC) hybrid cell lines resemble developing motor neurons. Dev Dyn, 194(3), 209-221. https://doi.org/10.1002/aja.1001940306

Chu, Y., Yue, X., Younger, S. T., Janowski, B. A., \& Corey, D. R. (2010). Involvement of argonaute proteins in gene silencing and activation by RNAs complementary to a non-coding transcript at the progesterone receptor promoter. Nucleic Acids Res, 38(21), 7736-7748. https://doi.org/10.1093/nar/gkq648

Cintron-Colon, A. F., Almeida-Alves, G., Boynton, A. M., \& Spitsbergen, J. M. (2020). GDNF synthesis, signaling, and retrograde transport in motor neurons. Cell Tissue Res, 382(1), 47-56. https://doi.org/10.1007/s00441-020-03287-6

Coulpier, M., Anders, J., \& Ibanez, C. F. (2002). Coordinated activation of autophosphorylation sites in the RET receptor tyrosine kinase: importance of tyrosine 1062 for GDNF mediated neuronal differentiation and survival. J Biol Chem, 277(3), 1991-1999. https://doi.org/10.1074/jbc.M107992200

Cox, J., \& Mann, M. (2008). MaxQuant enables high peptide identification rates, individualized p.p.b.-range mass accuracies and proteome-wide protein $\begin{array}{llll}\text { quantification. } & \text { Nat Biotechnol, 26(12), 1367-1372. }\end{array}$ https://doi.org/10.1038/nbt.1511

Crowder, R. J., Enomoto, H., Yang, M., Johnson, E. M., Jr., \& Milbrandt, J. (2004). Dok-6, a Novel p62 Dok family member, promotes Ret-mediated neurite outgrowth. J Biol Chem, 279(40), 42072-42081. https://doi.org/10.1074/jbc.M403726200

Danckwardt, S., Hentze, M. W., \& Kulozik, A. E. (2008). 3' end mRNA processing: molecular mechanisms and implications for health and disease. EMBOJ, 27(3), 482-498. https://doi.org/10.1038/sj.emboj.7601932

de Graaff, E., Srinivas, S., Kilkenny, C., D'Agati, V., Mankoo, B. S., Costantini, F., \& Pachnis, V. (2001). Differential activities of the RET tyrosine kinase receptor isoforms during mammalian embryogenesis. Genes Dev, 15(18), 2433-2444. https://doi.org/10.1101/gad.205001

De Vita, G., Melillo, R. M., Carlomagno, F., Visconti, R., Castellone, M. D., Bellacosa, A., Billaud, M., Fusco, A., Tsichlis, P. N., \& Santoro, M. (2000). Tyrosine 1062 of RET-MEN2A mediates activation of Akt (protein kinase B) and mitogenactivated protein kinase pathways leading to PC12 cell survival. Cancer Res, 60(14), 3727-3731. http://www.ncbi.nlm.nih.gov/pubmed/10919641

Deng, Z., Zhang, S., Gu, S., Ni, X., Zeng, W., \& Li, X. (2018). Useful Bicistronic Reporter System for Studying Poly(A) Site-Defining cis Elements and Regulation of Alternative Polyadenylation. Int $J$ Mol Sci, 19(1). https://doi.org/10.3390/ijms19010279

Deutsch, E. W., Bandeira, N., Sharma, V., Perez-Riverol, Y., Carver, J. J., Kundu, D. J., Garcia-Seisdedos, D., Jarnuczak, A. F., Hewapathirana, S., Pullman, B. S., Wertz, J., Sun, Z., Kawano, S., Okuda, S., Watanabe, Y., Hermjakob, H., MacLean, B., MacCoss, M. J., Zhu, Y., Ishihama, Y., \& Vizcaino, J. A. (2020). The ProteomeXchange consortium in 2020: enabling 'big data' approaches in proteomics. Nucleic Acids Res, 48(D1), D1145-D1152. https://doi.org/10.1093/nar/gkz984 
Di Giammartino, D. C., Nishida, K., \& Manley, J. L. (2011). Mechanisms and consequences of alternative polyadenylation. Mol Cell, 43(6), 853-866. https://doi.org/10.1016/j.molcel.2011.08.017

Dobin, A., Davis, C. A., Schlesinger, F., Drenkow, J., Zaleski, C., Jha, S., Batut, P., Chaisson, M., \& Gingeras, T. R. (2013). STAR: ultrafast universal RNA-seq aligner. Bioinformatics, 29(1), 15-21. https://doi.org/10.1093/bioinformatics/bts635

Elinger, D., Gabashvili, A., \& Levin, Y. (2019). Suspension Trapping (S-Trap) Is Compatible with Typical Protein Extraction Buffers and Detergents for BottomUp Proteomics. J Proteome Res, 18(3), 1441-1445. https://doi.org/10.1021/acs.jproteome.8b00891

Elkon, R., Ugalde, A. P., \& Agami, R. (2013). Alternative cleavage and polyadenylation: extent, regulation and function. Nat Rev Genet, 14(7), 496506. https://doi.org/10.1038/nrg3482

Enomoto, H., Crawford, P. A., Gorodinsky, A., Heuckeroth, R. O., Johnson, E. M., Jr., \& Milbrandt, J. (2001). RET signaling is essential for migration, axonal growth and axon guidance of developing sympathetic neurons. Development, 128(20), 3963-3974. http://www.ncbi.nlm.nih.gov/pubmed/11641220

Eulalio, A., Behm-Ansmant, I., \& Izaurralde, E. (2007). P bodies: at the crossroads of post-transcriptional pathways. Nat Rev Mol Cell Biol, 8(1), 9-22. https://doi.org/10.1038/nrm2080

Eulalio, A., Huntzinger, E., \& Izaurralde, E. (2008). GW 182 interaction with Argonaute is essential for miRNA-mediated translational repression and mRNA decay. Nat Struct Mol Biol, 15(4), 346-353. https://doi.org/10.1038/nsmb.1405

Fabian, M. R., Cieplak, M. K., Frank, F., Morita, M., Green, J., Srikumar, T., Nagar, B., Yamamoto, T., Raught, B., Duchaine, T. F., \& Sonenberg, N. (2011). miRNA-mediated deadenylation is orchestrated by GW182 through two conserved motifs that interact with CCR4-NOT. Nat Struct Mol Biol, 18(11), 1211-1217. https://doi.org/10.1038/nsmb.2149

Farack, L., Golan, M., Egozi, A., Dezorella, N., Bahar Halpern, K., Ben-Moshe, S., Garzilli, I., Toth, B., Roitman, L., Krizhanovsky, V., \& Itzkovitz, S. (2019). Transcriptional Heterogeneity of Beta Cells in the Intact Pancreas. Dev Cell, 48(1), 115-125 e114. https://doi.org/10.1016/j.devcel.2018.11.001

Fontes, M. M., Guvenek, A., Kawaguchi, R., Zheng, D., Huang, A., Ho, V. M., Chen, P. B., Liu, X., O'Dell, T. J., Coppola, G., Tian, B., \& Martin, K. C. (2017). Activity-Dependent Regulation of Alternative Cleavage and Polyadenylation During Hippocampal Long-Term Potentiation. Sci Rep, 7(1), 17377. https://doi.org/10.1038/s41598-017-17407-w

Franceschini, A., Szklarczyk, D., Frankild, S., Kuhn, M., Simonovic, M., Roth, A., Lin, J., Minguez, P., Bork, P., von Mering, C., \& Jensen, L. J. (2013). STRING v9.1: protein-protein interaction networks, with increased coverage and integration. Nucleic Acids Res, 4l(Database issue), D808-815. https://doi.org/10.1093/nar/gks1094

Frankish, A., Diekhans, M., Ferreira, A. M., Johnson, R., Jungreis, I., Loveland, J., Mudge, J. M., Sisu, C., Wright, J., Armstrong, J., Barnes, I., Berry, A., Bignell, A., Carbonell Sala, S., Chrast, J., Cunningham, F., Di Domenico, T., Donaldson, S., Fiddes, I. T., Garcia Giron, C., Gonzalez, J. M., Grego, T., Hardy, M., Hourlier, T., Hunt, T., Izuogu, O. G., Lagarde, J., Martin, F. J., Martinez, L., Mohanan, S., Muir, P., Navarro, F. C. P., Parker, A., Pei, B., Pozo, F., Ruffier, M., Schmitt, B. M., Stapleton, E., Suner, M. M., Sycheva, I., Uszczynska- 
Ratajczak, B., Xu, J., Yates, A., Zerbino, D., Zhang, Y., Aken, B., Choudhary, J. S., Gerstein, M., Guigo, R., Hubbard, T. J. P., Kellis, M., Paten, B., Reymond, A., Tress, M. L., \& Flicek, P. (2019). GENCODE reference annotation for the human and mouse genomes. Nucleic Acids Res, 47(D1), D766-D773. https://doi.org/10.1093/nar/gky955

Fu, Y., Chen, L., Chen, C., Ge, Y., Kang, M., Song, Z., Li, J., Feng, Y., Huo, Z., He, G., Hou, M., Chen, S., \& Xu, A. (2018). Crosstalk between alternative polyadenylation and miRNAs in the regulation of protein translational efficiency. Genome Res, 28(11), 1656-1663. https://doi.org/10.1101/gr.231506.117

Gagnon, K. T., Li, L., Chu, Y., Janowski, B. A., \& Corey, D. R. (2014). RNAi factors are present and active in human cell nuclei. Cell Rep, 6(1), 211-221. https://doi.org/10.1016/j.celrep.2013.12.013

Gould, T. W., Yonemura, S., Oppenheim, R. W., Ohmori, S., \& Enomoto, H. (2008). The neurotrophic effects of glial cell line-derived neurotrophic factor on spinal motoneurons are restricted to fusimotor subtypes. J Neurosci, 28(9), 2131-2146. https://doi.org/10.1523/JNEUROSCI.5185-07.2008

Grimm, J., Sachs, M., Britsch, S., Di Cesare, S., Schwarz-Romond, T., Alitalo, K., \& Birchmeier, W. (2001). Novel p62dok family members, dok-4 and dok-5, are substrates of the c-Ret receptor tyrosine kinase and mediate neuronal differentiation. $J \quad$ Cell Biol, $154(2), \quad 345-354$. https://doi.org/10.1083/jcb.200102032

Hammond, S. M., Boettcher, S., Caudy, A. A., Kobayashi, R., \& Hannon, G. J. (2001). Argonaute2, a link between genetic and biochemical analyses of RNAi. Science, 293(5532), 1146-1150. https://doi.org/10.1126/science.1064023

Hayashi, H., Ichihara, M., Iwashita, T., Murakami, H., Shimono, Y., Kawai, K., Kurokawa, K., Murakumo, Y., Imai, T., Funahashi, H., Nakao, A., \& Takahashi, M. (2000). Characterization of intracellular signals via tyrosine 1062 in RET activated by glial cell line-derived neurotrophic factor. Oncogene, 19(39), 44694475. https://doi.org/10.1038/sj.onc.1203799

Heanue, T. A., \& Pachnis, V. (2008). Ret isoform function and marker gene expression in the enteric nervous system is conserved across diverse vertebrate species. Mech Dev, 125(8), 687-699. https://doi.org/10.1016/j.mod.2008.04.006

Hickey, J. G., Myers, S. M., Tian, X., Zhu, S. J., JL, V. S., Andrew, S. D., Richardson, D. S., Brettschneider, J., \& Mulligan, L. M. (2009). RET-mediated gene expression pattern is affected by isoform but not oncogenic mutation. Genes Chromosomes Cancer, 48(5), 429-440. https://doi.org/10.1002/gcc.20653

Hock, J., \& Meister, G. (2008). The Argonaute protein family. Genome Biol, 9(2), 210. https://doi.org/10.1186/gb-2008-9-2-210

Honma, Y., Kawano, M., Kohsaka, S., \& Ogawa, M. (2010). Axonal projections of mechanoreceptive dorsal root ganglion neurons depend on Ret. Development, 137(14), 2319-2328. https://doi.org/10.1242/dev.046995

Huang da, W., Sherman, B. T., \& Lempicki, R. A. (2009). Systematic and integrative analysis of large gene lists using DAVID bioinformatics resources. Nat Protoc, 4(1), 44-57. https://doi.org/10.1038/nprot.2008.211

Hwang, H. W., Saito, Y., Park, C. Y., Blachere, N. E., Tajima, Y., Fak, J. J., ZuckerScharff, I., \& Darnell, R. B. (2017). cTag-PAPERCLIP Reveals Alternative Polyadenylation Promotes Cell-Type Specific Protein Diversity and Shifts Araf Isoforms with Microglia Activation. Neuron, 95(6), 1334-1349 e1335. https://doi.org/10.1016/j.neuron.2017.08.024 
Ibanez, C. F. (2013). Structure and physiology of the RET receptor tyrosine kinase. Cold Spring Harb Perspect Biol, 5(2). https://doi.org/10.1101/cshperspect.a009134

Ibanez, C. F., \& Andressoo, J. O. (2017). Biology of GDNF and its receptors Relevance for disorders of the central nervous system. Neurobiol Dis, 97(Pt B), 80-89. https://doi.org/10.1016/j.nbd.2016.01.021

Itzkovitz, S., \& van Oudenaarden, A. (2011). Validating transcripts with probes and imaging technology. Nat Methods, $8(4 \quad$ Suppl), S12-19. https://doi.org/10.1038/nmeth.1573

Jakymiw, A., Lian, S., Eystathioy, T., Li, S., Satoh, M., Hamel, J. C., Fritzler, M. J., \& Chan, E. K. (2005). Disruption of GW bodies impairs mammalian RNA interference. Nat Cell Biol, 7(12), 1267-1274. https://doi.org/10.1038/ncb1334

Janowski, B. A., Huffman, K. E., Schwartz, J. C., Ram, R., Nordsell, R., Shames, D. S., Minna, J. D., \& Corey, D. R. (2006). Involvement of AGO1 and AGO2 in mammalian transcriptional silencing. Nat Struct Mol Biol, 13(9), 787-792. https://doi.org/10.1038/nsmb1140

Janowski, B. A., Younger, S. T., Hardy, D. B., Ram, R., Huffman, K. E., \& Corey, D. R. (2007). Activating gene expression in mammalian cells with promotertargeted duplex RNAs. Nat Chem Biol, 3(3), 166-173. https://doi.org/10.1038/nchembio860

Kalantari, R., Hicks, J. A., Li, L., Gagnon, K. T., Sridhara, V., Lemoff, A., Mirzaei, H., \& Corey, D. R. (2016). Stable association of RNAi machinery is conserved between the cytoplasm and nucleus of human cells. RNA, 22(7), 1085-1098. https://doi.org/10.1261/rna.056499.116

Kaplan, D. R., \& Miller, F. D. (2000). Neurotrophin signal transduction in the nervous system. Curr Opin Neurobiol, 10(3), 381-391. https://doi.org/10.1016/s09594388(00)00092-1

Kramer, E. R., Knott, L., Su, F., Dessaud, E., Krull, C. E., Helmbacher, F., \& Klein, R. (2006). Cooperation between GDNF/Ret and ephrinA/EphA4 signals for motoraxon pathway selection in the limb. Neuron, 50(1), 35-47. https://doi.org/10.1016/j.neuron.2006.02.020

Kramer, E. R., \& Liss, B. (2015). GDNF-Ret signaling in midbrain dopaminergic neurons and its implication for Parkinson disease. FEBS Lett, 589(24 Pt A), 3760-3772. https://doi.org/10.1016/j.febslet.2015.11.006

Lee, K. Y., Samy, E. T., Sham, M. H., Tam, P. K., \& Lui, V. C. (2003). 3' Splicing variants of ret receptor tyrosine kinase are differentially expressed in mouse embryos and in adult mice. Biochim Biophys Acta, 1627(1), 26-38. https://doi.org/10.1016/s0167-4781(03)00068-x

Lian, E. Y., Maritan, S. M., Cockburn, J. G., Kasaian, K., Crupi, M. J., Hurlbut, D., Jones, S. J., Wiseman, S. M., \& Mulligan, L. M. (2017). Differential roles of RET isoforms in medullary and papillary thyroid carcinomas. Endocr Relat Cancer, 24(1), 53-69. https://doi.org/10.1530/ERC-16-0393

Licatalosi, D. D., Mele, A., Fak, J. J., Ule, J., Kayikci, M., Chi, S. W., Clark, T. A., Schweitzer, A. C., Blume, J. E., Wang, X., Darnell, J. C., \& Darnell, R. B. (2008). HITS-CLIP yields genome-wide insights into brain alternative RNA processing. Nature, 456(7221), 464-469. https://doi.org/10.1038/nature07488

Liu, J., Carmell, M. A., Rivas, F. V., Marsden, C. G., Thomson, J. M., Song, J. J., Hammond, S. M., Joshua-Tor, L., \& Hannon, G. J. (2004). Argonaute2 is the 
catalytic engine of mammalian RNAi. Science, 305(5689), 1437-1441. https://doi.org/10.1126/science.1102513

Liu, J., Rivas, F. V., Wohlschlegel, J., Yates, J. R., 3rd, Parker, R., \& Hannon, G. J. (2005). A role for the P-body component GW182 in microRNA function. Nat Cell Biol, 7(12), 1261-1266. https://doi.org/10.1038/ncb1333

Liu, J., Valencia-Sanchez, M. A., Hannon, G. J., \& Parker, R. (2005). MicroRNAdependent localization of targeted mRNAs to mammalian P-bodies. Nat Cell Biol, 7(7), 719-723. https://doi.org/10.1038/ncb1274

Lundgren, T. K., Scott, R. P., Smith, M., Pawson, T., \& Ernfors, P. (2006). Engineering the recruitment of phosphotyrosine binding domain-containing adaptor proteins reveals distinct roles for RET receptor-mediated cell survival. J Biol Chem, 281(40), 29886-29896. https://doi.org/10.1074/jbc.M600473200

Lyubimova, A., Itzkovitz, S., Junker, J. P., Fan, Z. P., Wu, X., \& van Oudenaarden, A. (2013). Single-molecule mRNA detection and counting in mammalian tissue. Nat Protoc, 8(9), 1743-1758. https://doi.org/10.1038/nprot.2013.109

MacDonald, C. C. (2019). Tissue-specific mechanisms of alternative polyadenylation: Testis, brain, and beyond (2018 update). Wiley Interdiscip Rev RNA, 10(4), e1526. https://doi.org/10.1002/wrna.1526

MacDonald, C. C., \& Redondo, J. L. (2002). Reexamining the polyadenylation signal: were we wrong about AAUAAA? Mol Cell Endocrinol, 190(1-2), 1-8. https://doi.org/10.1016/s0303-7207(02)00044-8

Mansfield, K. D., \& Keene, J. D. (2012). Neuron-specific ELAV/Hu proteins suppress HuR mRNA during neuronal differentiation by alternative polyadenylation. Nucleic Acids Res, 40(6), 2734-2746. https://doi.org/10.1093/nar/gkr1114

Martinez, F. J., Pratt, G. A., Van Nostrand, E. L., Batra, R., Huelga, S. C., Kapeli, K., Freese, P., Chun, S. J., Ling, K., Gelboin-Burkhart, C., Fijany, L., Wang, H. C., Nussbacher, J. K., Broski, S. M., Kim, H. J., Lardelli, R., Sundararaman, B., Donohue, J. P., Javaherian, A., Lykke-Andersen, J., Finkbeiner, S., Bennett, C. F., Ares, M., Jr., Burge, C. B., Taylor, J. P., Rigo, F., \& Yeo, G. W. (2016). Protein-RNA Networks Regulated by Normal and ALS-Associated Mutant HNRNPA2B1 in the Nervous System. Neuron, 92(4), 780-795. https://doi.org/10.1016/j.neuron.2016.09.050

Masuda, A., Takeda, J., Okuno, T., Okamoto, T., Ohkawara, B., Ito, M., Ishigaki, S., Sobue, G., \& Ohno, K. (2015). Position-specific binding of FUS to nascent RNA regulates mRNA length. Genes Dev, 29(10), 1045-1057. https://doi.org/10.1101/gad.255737.114

Meister, G. (2013). Argonaute proteins: functional insights and emerging roles. Nat Rev Genet, 14(7), 447-459. https://doi.org/10.1038/nrg3462

Meister, G., \& Tuschl, T. (2004). Mechanisms of gene silencing by double-stranded RNA. Nature, 431(7006), 343-349. https://doi.org/10.1038/nature02873

Melamed, Z., Lopez-Erauskin, J., Baughn, M. W., Zhang, O., Drenner, K., Sun, Y., Freyermuth, F., McMahon, M. A., Beccari, M. S., Artates, J. W., Ohkubo, T., Rodriguez, M., Lin, N., Wu, D., Bennett, C. F., Rigo, F., Da Cruz, S., Ravits, J., Lagier-Tourenne, C., \& Cleveland, D. W. (2019). Premature polyadenylation-mediated loss of stathmin-2 is a hallmark of TDP-43dependent neurodegeneration. Nat Neurosci, 22(2), 180-190. https://doi.org/10.1038/s41593-018-0293-z

Milligan, C., \& Gifondorwa, D. (2011). Isolation and culture of postnatal spinal motoneurons. Methods Mol Biol, 793, 77-85. https://doi.org/10.1007/978-1$\underline{61779-328-8 \quad 5}$ 
Miura, P., Shenker, S., Andreu-Agullo, C., Westholm, J. O., \& Lai, E. C. (2013). Widespread and extensive lengthening of 3' UTRs in the mammalian brain. Genome Res, 23(5), 812-825. https://doi.org/10.1101/gr.146886.112

Moore, M. J., Scheel, T. K., Luna, J. M., Park, C. Y., Fak, J. J., Nishiuchi, E., Rice, C. M., \& Darnell, R. B. (2015). miRNA-target chimeras reveal miRNA 3'-end pairing as a major determinant of Argonaute target specificity. Nat Commun, 6, 8864. https://doi.org/10.1038/ncomms9864

Nussbacher, J. K., Tabet, R., Yeo, G. W., \& Lagier-Tourenne, C. (2019). Disruption of RNA Metabolism in Neurological Diseases and Emerging Therapeutic Interventions. Neuron, 102(2), 294-320. https://doi.org/10.1016/j.neuron.2019.03.014

Pachnis, V., Mankoo, B., \& Costantini, F. (1993). Expression of the c-ret protooncogene during mouse embryogenesis. Development, 119(4), 1005-1017. http://www.ncbi.nlm.nih.gov/pubmed/8306871

Perez-Riverol, Y., Csordas, A., Bai, J., Bernal-Llinares, M., Hewapathirana, S., Kundu, D. J., Inuganti, A., Griss, J., Mayer, G., Eisenacher, M., Perez, E., Uszkoreit, J., Pfeuffer, J., Sachsenberg, T., Yilmaz, S., Tiwary, S., Cox, J., Audain, E., Walzer, M., Jarnuczak, A. F., Ternent, T., Brazma, A., \& Vizcaino, J. A. (2019). The PRIDE database and related tools and resources in 2019: improving support for quantification data. Nucleic Acids Res, 47(D1), D442-D450. https://doi.org/10.1093/nar/gky1106

Perrinjaquet, M., Vilar, M., \& Ibanez, C. F. (2010). Protein-tyrosine phosphatase SHP2 contributes to GDNF neurotrophic activity through direct binding to phosphoTyr687 in the RET receptor tyrosine kinase. J Biol Chem, 285(41), 3186731875. https://doi.org/10.1074/jbc.M110.144923

Prudencio, M., Belzil, V. V., Batra, R., Ross, C. A., Gendron, T. F., Pregent, L. J., Murray, M. E., Overstreet, K. K., Piazza-Johnston, A. E., Desaro, P., Bieniek, K. F., DeTure, M., Lee, W. C., Biendarra, S. M., Davis, M. D., Baker, M. C., Perkerson, R. B., van Blitterswijk, M., Stetler, C. T., Rademakers, R., Link, C. D., Dickson, D. W., Boylan, K. B., Li, H., \& Petrucelli, L. (2015). Distinct brain transcriptome profiles in C9orf72-associated and sporadic ALS. Nat Neurosci, 18(8), 1175-1182. https://doi.org/10.1038/nn.4065

Raj, A., van den Bogaard, P., Rifkin, S. A., van Oudenaarden, A., \& Tyagi, S. (2008). Imaging individual mRNA molecules using multiple singly labeled probes. Nat Methods, 5(10), 877-879. https://doi.org/10.1038/nmeth.1253

Rehwinkel, J., Behm-Ansmant, I., Gatfield, D., \& Izaurralde, E. (2005). A crucial role for GW182 and the DCP1:DCP2 decapping complex in miRNA-mediated gene silencing. $R N A, 11(11), 1640-1647$. https://doi.org/10.1261/rna.2191905

Richardson, D. S., Rodrigues, D. M., Hyndman, B. D., Crupi, M. J., Nicolescu, A. C., \& Mulligan, L. M. (2012). Alternative splicing results in RET isoforms with distinct trafficking properties. Mol Biol Cell, 23(19), 3838-3850. https://doi.org/10.1091/mbc.E12-02-0114

Robb, G. B., Brown, K. M., Khurana, J., \& Rana, T. M. (2005). Specific and potent RNAi in the nucleus of human cells. Nat Struct Mol Biol, 12(2), 133-137. https://doi.org/10.1038/nsmb886

Romei, C., Ciampi, R., \& Elisei, R. (2016). A comprehensive overview of the role of the RET proto-oncogene in thyroid carcinoma. Nat Rev Endocrinol, 12(4), 192202. https://doi.org/10.1038/nrendo.2016.11

Rossel, M., Pasini, A., Chappuis, S., Geneste, O., Fournier, L., Schuffenecker, I., Takahashi, M., van Grunsven, L. A., Urdiales, J. L., Rudkin, B. B., Lenoir, G. 
M., \& Billaud, M. (1997). Distinct biological properties of two RET isoforms activated by MEN 2A and MEN 2B mutations. Oncogene, 14(3), 265-275. https://doi.org/10.1038/sj.onc.1200831

Rot, G., Wang, Z., Huppertz, I., Modic, M., Lence, T., Hallegger, M., Haberman, N., Curk, T., von Mering, C., \& Ule, J. (2017). High-Resolution RNA Maps Suggest Common Principles of Splicing and Polyadenylation Regulation by TDP-43. Cell Rep, 19(5), 1056-1067. https://doi.org/10.1016/j.celrep.2017.04.028

Rudel, S., Flatley, A., Weinmann, L., Kremmer, E., \& Meister, G. (2008). A multifunctional human Argonaute2-specific monoclonal antibody. RNA, 14(6), 1244-1253. https://doi.org/10.1261/rna.973808

Runeberg-Roos, P., \& Saarma, M. (2007). Neurotrophic factor receptor RET: structure, cell biology, and inherited diseases. Ann Med, 39(8), 572-580. https://doi.org/10.1080/07853890701646256

Ryu, H., Jeon, G. S., Cashman, N. R., Kowall, N. W., \& Lee, J. (2011). Differential expression of c-Ret in motor neurons versus non-neuronal cells is linked to the pathogenesis of ALS. Lab Invest, 91(3), 342-352. https://doi.org/10.1038/labinvest.2010.203

Sarshad, A. A., Juan, A. H., Muler, A. I. C., Anastasakis, D. G., Wang, X. T., Genzor, P., Feng, X. S., Tsai, P. F., Sun, H. W., Haase, A. D., Sartorelli, V., \& Hafner, M. (2018). Argonaute-miRNA Complexes Silence Target mRNAs in the Nucleus of Mammalian Stem Cells. Molecular Cell, 71(6), 1040-+. https://doi.org/10.1016/j.molcel.2018.07.020

Schindelin, J., Arganda-Carreras, I., Frise, E., Kaynig, V., Longair, M., Pietzsch, T., Preibisch, S., Rueden, C., Saalfeld, S., Schmid, B., Tinevez, J. Y., White, D. J., Hartenstein, V., Eliceiri, K., Tomancak, P., \& Cardona, A. (2012). Fiji: an opensource platform for biological-image analysis. Nat Methods, 9(7), 676-682. https://doi.org/10.1038/nmeth.2019

Schraivogel, D., Schindler, S. G., Danner, J., Kremmer, E., Pfaff, J., Hannus, S., Depping, R., \& Meister, G. (2015). Importin-beta facilitates nuclear import of human GW proteins and balances cytoplasmic gene silencing protein levels. Nucleic Acids Res, 43(15), 7447-7461. https://doi.org/10.1093/nar/gkv705

Schwartz, J. C., Ebmeier, C. C., Podell, E. R., Heimiller, J., Taatjes, D. J., \& Cech, T. R. (2012). FUS binds the CTD of RNA polymerase II and regulates its phosphorylation at Ser2. Genes Dev, 26(24), 2690-2695. https://doi.org/10.1101/gad.204602.112

Segouffin-Cariou, C., \& Billaud, M. (2000). Transforming ability of MEN2A-RET requires activation of the phosphatidylinositol 3-kinase/AKT signaling $\begin{array}{llll}\text { pathway. } J \text { Biol } & \text { Chem, 275(5), }\end{array}$ https://doi.org/10.1074/jbc. 275.5 .3568

Sen, G. L., \& Blau, H. M. (2005). Argonaute 2/RISC resides in sites of mammalian mRNA decay known as cytoplasmic bodies. Nat Cell Biol, 7(6), 633-636. https://doi.org/10.1038/ncb1265

Shalit, T., Elinger, D., Savidor, A., Gabashvili, A., \& Levin, Y. (2015). MS1-based label-free proteomics using a quadrupole orbitrap mass spectrometer. $J$ Proteome Res, 14(4), 1979-1986. https://doi.org/10.1021/pr501045t

Taliaferro, J. M., Vidaki, M., Oliveira, R., Olson, S., Zhan, L., Saxena, T., Wang, E. T., Graveley, B. R., Gertler, F. B., Swanson, M. S., \& Burge, C. B. (2016). Distal Alternative Last Exons Localize mRNAs to Neural Projections. Mol Cell, 61(6), 821-833. https://doi.org/10.1016/j.molcel.2016.01.020 
Terenzio, M., Koley, S., Samra, N., Rishal, I., Zhao, Q., Sahoo, P. K., Urisman, A., Marvaldi, L., Oses-Prieto, J. A., Forester, C., Gomes, C., Kalinski, A. L., Di Pizio, A., Doron-Mandel, E., Perry, R. B., Koppel, I., Twiss, J. L., Burlingame, A. L., \& Fainzilber, M. (2018). Locally translated mTOR controls axonal local translation in nerve injury. Science, 359(6382), 1416-1421. https://doi.org/10.1126/science.aan1053

Thul, P. J., Akesson, L., Wiking, M., Mahdessian, D., Geladaki, A., Ait Blal, H., Alm, T., Asplund, A., Bjork, L., Breckels, L. M., Backstrom, A., Danielsson, F., Fagerberg, L., Fall, J., Gatto, L., Gnann, C., Hober, S., Hjelmare, M., Johansson, F., Lee, S., Lindskog, C., Mulder, J., Mulvey, C. M., Nilsson, P., Oksvold, P., Rockberg, J., Schutten, R., Schwenk, J. M., Sivertsson, A., Sjostedt, E., Skogs, M., Stadler, C., Sullivan, D. P., Tegel, H., Winsnes, C., Zhang, C., Zwahlen, M., Mardinoglu, A., Ponten, F., von Feilitzen, K., Lilley, K. S., Uhlen, M., \& Lundberg, E. (2017). A subcellular map of the human proteome. Science, 356(6340). https://doi.org/10.1126/science.aal3321

Tian, B., \& Graber, J. H. (2012). Signals for pre-mRNA cleavage and polyadenylation. Wiley Interdiscip Rev RNA, 3(3), 385-396. https://doi.org/10.1002/wrna.116

Tian, B., \& Manley, J. L. (2017). Alternative polyadenylation of mRNA precursors. Nat Rev Mol Cell Biol, 18(1), 18-30. https://doi.org/10.1038/nrm.2016.116

Tsui-Pierchala, B. A., Ahrens, R. C., Crowder, R. J., Milbrandt, J., \& Johnson, E. M., Jr. (2002). The long and short isoforms of Ret function as independent signaling complexes. $J$ Biol Chem, 277(37), 34618-34625. https://doi.org/10.1074/jbc.M203580200

Tsui, C. C., \& Pierchala, B. A. (2010). The differential axonal degradation of Ret accounts for cell-type-specific function of glial cell line-derived neurotrophic factor as a retrograde survival factor. $J$ Neurosci, 30(15), 5149-5158. https://doi.org/10.1523/JNEUROSCI.5246-09.2010

Tuschl, T., Zamore, P. D., Lehmann, R., Bartel, D. P., \& Sharp, P. A. (1999). Targeted mRNA degradation by double-stranded RNA in vitro. Genes Dev, 13(24), 31913197. http://www.ncbi.nlm.nih.gov/pubmed/10617568

Tuttle, A., Drerup, C. M., Marra, M., McGraw, H., \& Nechiporuk, A. V. (2019). Retrograde Ret signaling controls sensory pioneer axon outgrowth. Elife, 8 . https://doi.org/10.7554/eLife.46092

Tyanova, S., Temu, T., Sinitcyn, P., Carlson, A., Hein, M. Y., Geiger, T., Mann, M., \& Cox, J. (2016). The Perseus computational platform for comprehensive analysis of (prote)omics data. Nat Methods, 13(9), 731-740. https://doi.org/10.1038/nmeth.3901

Ule, J., Jensen, K. B., Ruggiu, M., Mele, A., Ule, A., \& Darnell, R. B. (2003). CLIP identifies Nova-regulated RNA networks in the brain. Science, 302(5648), 1212-1215. https://doi.org/10.1126/science.1090095

Ulitsky, I., Shkumatava, A., Jan, C. H., Subtelny, A. O., Koppstein, D., Bell, G. W., Sive, H., \& Bartel, D. P. (2012). Extensive alternative polyadenylation during zebrafish development. Genome Res, 22(10), 2054-2066. https://doi.org/10.1101/gr.139733.112

Unger, T., Jacobovitch, Y., Dantes, A., Bernheim, R., \& Peleg, Y. (2010). Applications of the Restriction Free (RF) cloning procedure for molecular manipulations and

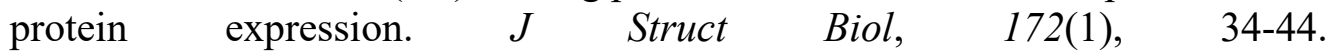
https://doi.org/10.1016/j.jsb.2010.06.016 
Wei, Y., Li, L., Wang, D., Zhang, C. Y., \& Zen, K. (2014). Importin 8 regulates the transport of mature microRNAs into the cell nucleus. J Biol Chem, 289(15), 10270-10275. https://doi.org/10.1074/jbc.C113.541417

Wong, A., Bogni, S., Kotka, P., de Graaff, E., D'Agati, V., Costantini, F., \& Pachnis, V. (2005). Phosphotyrosine 1062 is critical for the in vivo activity of the Ret9 receptor tyrosine kinase isoform. Mol Cell Biol, 25(21), 9661-9673. https://doi.org/10.1128/MCB.25.21.9661-9673.2005

Zahavi, E. E., Ionescu, A., Gluska, S., Gradus, T., Ben-Yaakov, K., \& Perlson, E. (2015). A compartmentalized microfluidic neuromuscular co-culture system reveals spatial aspects of GDNF functions. J Cell Sci, 128(6), 1241-1252. https://doi.org/10.1242/jcs.167544

Zamore, P. D., Tuschl, T., Sharp, P. A., \& Bartel, D. P. (2000). RNAi: double-stranded RNA directs the ATP-dependent cleavage of mRNA at 21 to 23 nucleotide intervals. Cell, 101(1), 25-33. https://doi.org/10.1016/S0092-8674(00)80620-0

Zekri, L., Huntzinger, E., Heimstadt, S., \& Izaurralde, E. (2009). The silencing domain of GW182 interacts with PABPC1 to promote translational repression and degradation of microRNA targets and is required for target release. Mol Cell Biol, 29(23), 6220-6231. https://doi.org/10.1128/MCB.01081-09

Zhang, J., \& Huang, E. J. (2006). Dynamic expression of neurotrophic factor receptors in postnatal spinal motoneurons and in mouse model of ALS. J Neurobiol, 66(8), 882-895. https://doi.org/10.1002/neu.20269

APA and focus on the GDNF receptor, RET, as a key target for AGO2- 


\section{Supplementary Figures}
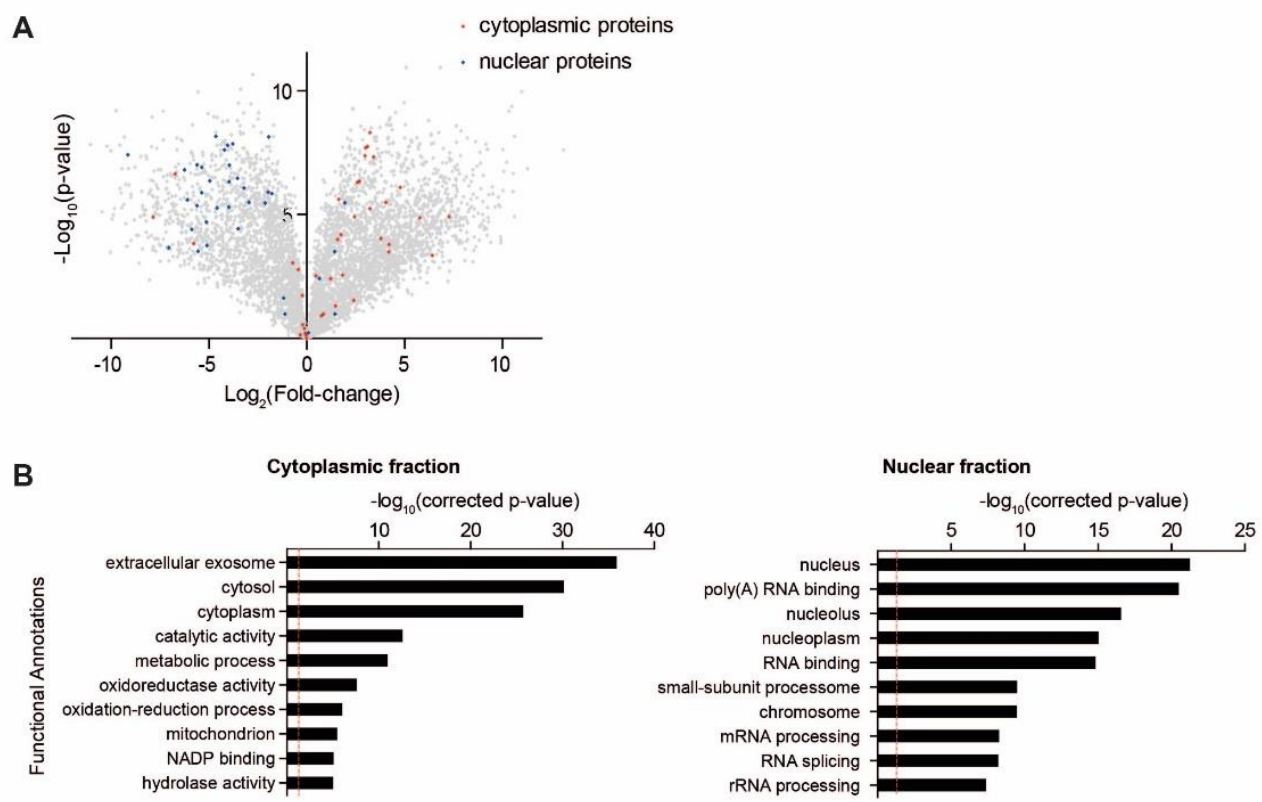

Supplementary Figure 1. A platform for characterizing AGO2 protein-interactions in neuronal nuclei. (A) Volcano plot depicting the distribution of all proteins identified by MS analysis of cytoplasmic and nuclear fractions lysates. $x$ - axis: $\log _{2}$ fold change of label-free peptide quantification values in cytoplasmic fraction versus nuclear fraction; y axis: $\log _{10}$ of two-tailed Student's t-test p-value. Grey-all proteins; Red/Blue -cytoplasmic/nuclear marker proteins obtained from protein atlas (Thul et al., 2017). (B) Gene ontology analysis of proteins that are enriched in either nuclear (top panel) or cytoplasmic (lower panel) fractions ( $>100$ fold), shown as $-\log _{10}$ (Bonferroni corrected p-value) of pathway enrichment (logarithmic scale). Dashed red line indicates a p-value of 0.05. Analysis performed with DAVID 6.7 bioinformatic database(Huang da et al., 2009). Categories enriched in each fraction provide further support of efficient nuclear-cytoplasmic separation. 


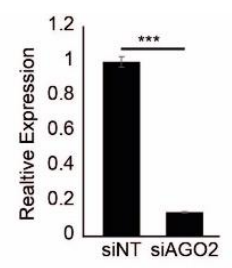

Supplementary Figure 2. Quantitative Validation of AGO2-KD using siAGO2. Real-time PCR quantification of Ago2 mRNA in NSC-34 cells treated with siAGO2 vs siNon-Targeting (siNT) as control. Average \pm SEM of 3 repeats, data normalized to siNT. Two-tailed Student's $t$-test $\mathrm{p}$-value $* \leq 0.05, * * \leq 0.01, * * * \leq 0.001 ; \mathrm{p}$-value $=0.000013854$.

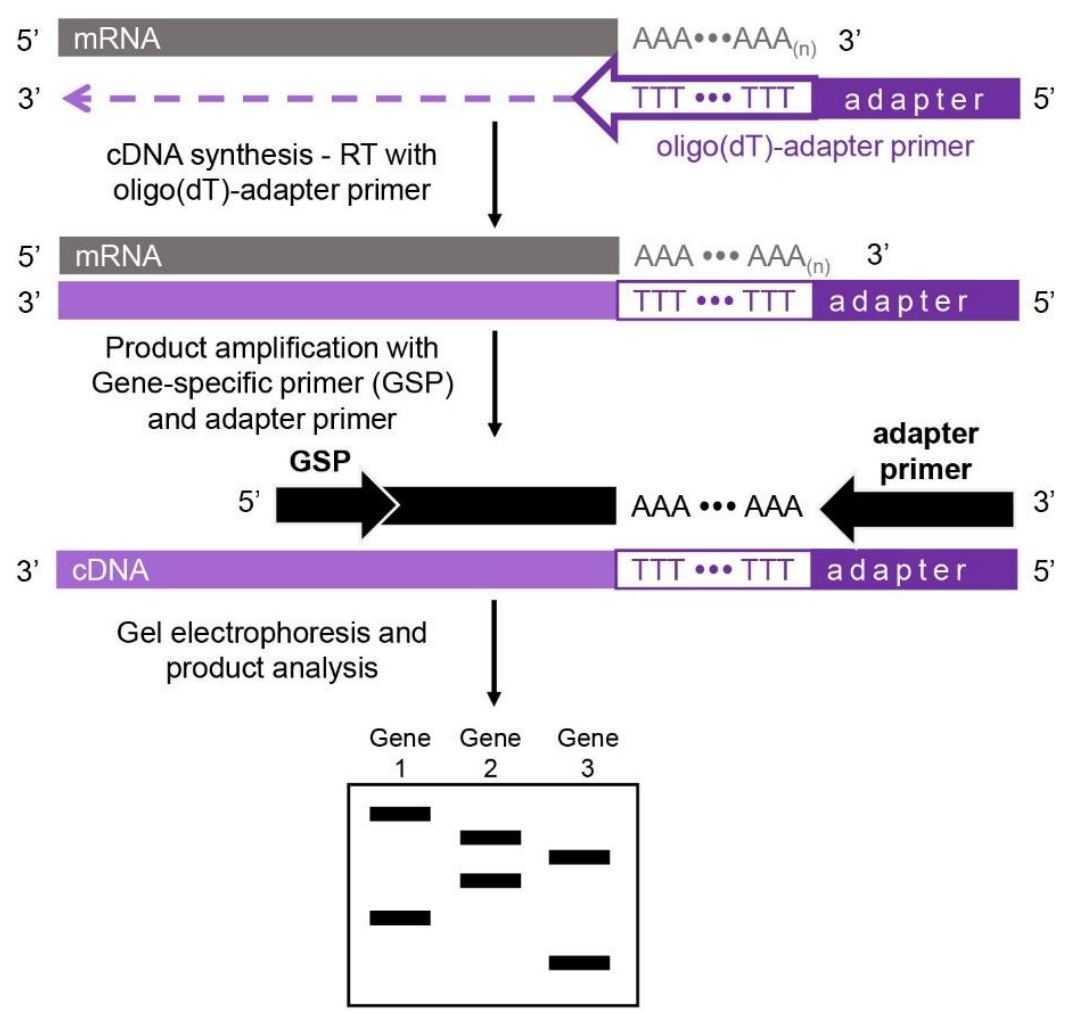

Supplementary Figure 3. 3'RACE-like PCR demonstration of APA. An oligo(dT)-VN primer mix (V-any nucleotide but $\mathrm{T}, \mathrm{N}$ - any nucleotide) planned to capture transcript $3^{\prime}$ end was used to generate cDNA with an adapter sequence subsequently downstream of the poly(A) tail. Gene-specific PCR reaction was then performed and analyzed by gel electrophoresis depict differential usage of PAS, and hence different poly(A) tail length. 

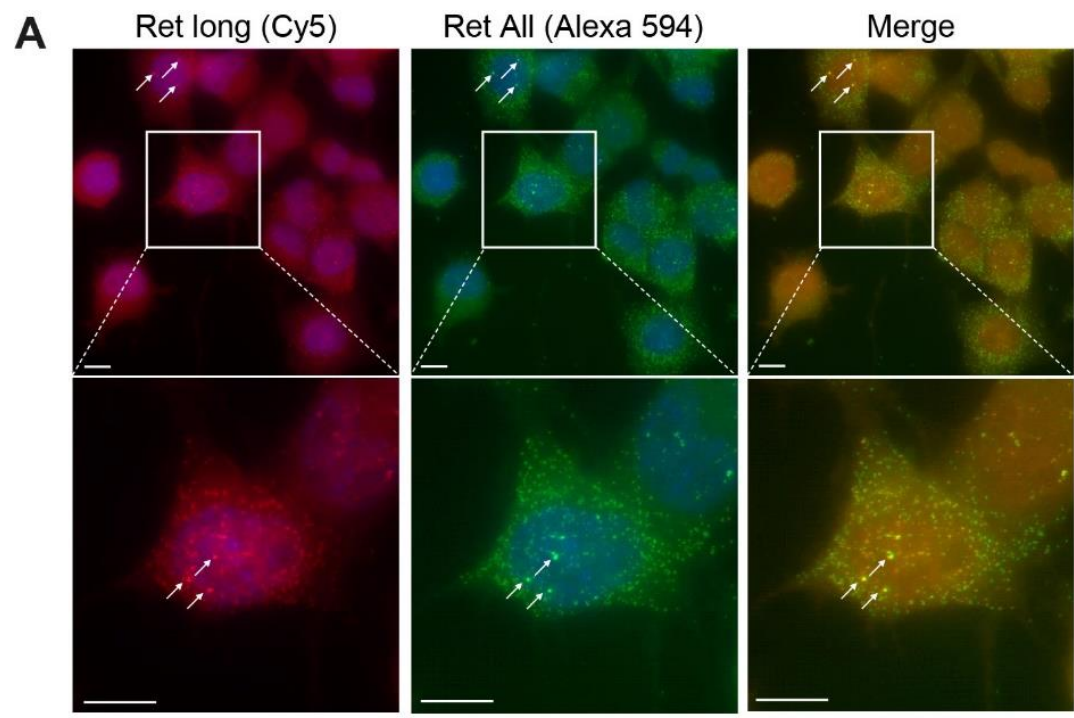

B
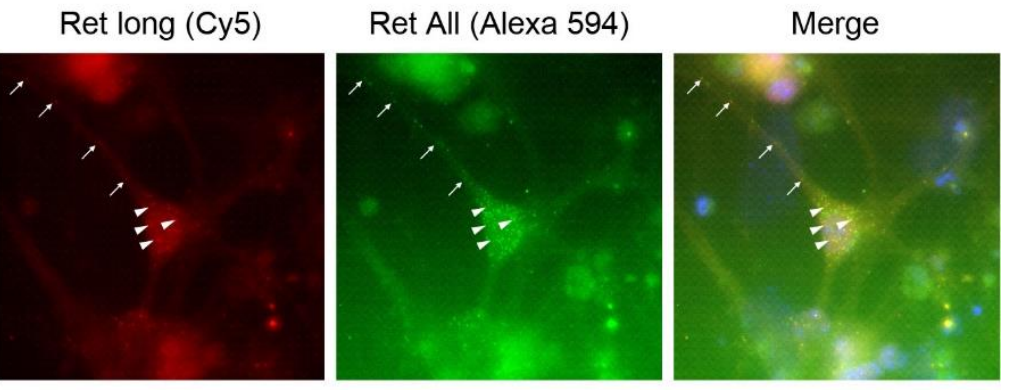

Supplementary Figure 4. Ret APA isoforms smFISH study in mouse neurons. smFISH probes detect only the long variant (cy5, red) or both long and short variants (Alexa 594, green) of Ret. Arrowheads and arrows depict the long variant in NSC-34 cells (A) and in soma and neurites, respectively, in mouse primary motor neurons (B). scale bar - $10 \mu \mathrm{M}$. 